OPEN ACCESS

Edited by:

Dimitrios Georgios Karpouzas, University of Thessaly, Greece

Reviewed by: Antonis Chatzinotas, Helmholtz Centre for Environmental

Research - UFZ, Germany Anna Irini Koukkou,

University of loannina, Greece

*Correspondence: Aurélie Cébron aurelie.cebron@univ-lorraine.fr

${ }^{\dagger}$ Present Address:

Francois Thomas, Centre National de la Recherche Scientifique, UMR8227, Integrative Biology of Marine Models, Station Biologique de Roscoff, Roscoff,

France

Specialty section:

This article was submitted to Systems Microbiology,

a section of the journa

Frontiers in Microbiology

Received: 15 December 2015 Accepted: 18 January 2016

Published: 05 February 2016

Citation:

Thomas F and Cébron A (2016) Short-Term Rhizosphere Effect on Available Carbon Sources,

Phenanthrene Degradation, and Active Microbiome in an Aged-Contaminated Industrial Soil. Front. Microbiol. 7:92 doi: 10.3389/fmicb.2016.00092

\section{Short-Term Rhizosphere Effect on Available Carbon Sources, Phenanthrene Degradation, and Active Microbiome in an Aged-Contaminated Industrial Soil}

\author{
François Thomas ${ }^{1,2 \dagger}$ and Aurélie Cébron ${ }^{1,2 *}$ \\ ${ }^{1}$ CNRS, LIEC UMR7360, Faculté des Sciences et Technologies, Vandoeuvre-lés-Nancy, France, ${ }^{2}$ Université de Lorraine, \\ LIEC UMR7360, Faculté des Sciences et Technologies, Vandoeuvre-lés-Nancy, France
}

Over the last decades, understanding of the effects of plants on soil microbiomes has greatly advanced. However, knowledge on the assembly of rhizospheric communities in aged-contaminated industrial soils is still limited, especially with regard to transcriptionally active microbiomes and their link to the quality or quantity of carbon sources. We compared the short-term (2-10 days) dynamics of bacterial communities and potential PAH-degrading bacteria in bare or ryegrass-planted aged-contaminated soil spiked with phenanthrene, put in relation with dissolved organic carbon (DOC) sources and polycyclic aromatic hydrocarbon (PAH) pollution. Both resident and active bacterial communities (analyzed from DNA and RNA, respectively) showed higher species richness and smaller dispersion between replicates in planted soils. Root development strongly favored the activity of Pseudomonadales within the first 2 days, and of members of Actinobacteria, Caulobacterales, Rhizobiales, and Xanthomonadales within 6-10 days. Plants slowed down the dissipation of phenanthrene, while root exudation provided a cocktail of labile substrates that might preferentially fuel microbial growth. Although the abundance of $\mathrm{PAH}$-degrading genes increased in planted soil, their transcription level stayed similar to bare soil. In addition, network analysis revealed that plants induced an early shift in the identity of potential phenanthrene degraders, which might influence PAH dissipation on the long-term.

\section{Keywords: rhizosphere, plant root exudates, DNA/RNA, PAH, bacterial diversity, ryegrass (Lolium)}

\section{INTRODUCTION}

During the last decade, progress in "meta-omics" approaches has greatly improved the understanding of bacterial communities in the rhizosphere of various plant species, revealing the complexity of plant-microbes interactions and their importance for soil ecosystems (ReinholdHurek et al., 2015). Most studies focused on unpolluted soil (Trivedi et al., 2012; Chaparro et al., 2014; Mendes et al., 2014), providing a fundamental knowledge of how plants shape the soil microbiome in the absence of perturbation. Comparatively little is known about the identity, 
activity, and short-term temporal dynamics of rhizospheric assemblages in contaminated habitats, although this could have significant impact for soil remediation on the longterm. Polycyclic aromatic hydrocarbons (PAHs) are one of the most abundant anthropogenic hazardous molecules in the environment. They consist of two or more fused aromatic rings produced from the incomplete combustion of organic matter, for instance in coking plants or gas factories. Over the past century, industrial activities left large areas of aged PAH-contaminated soil, threatening both ecosystems functions and human health. The high persistence of PAHs and their toxic, mutagenic, and carcinogenic properties have motivated the search for efficient remediation strategies (Gan et al., 2009). Among these, rhizoremediation of organic pollutants is based on the beneficial effects of plants on the degradation by soil microorganisms (Kuiper et al., 2004). This positive rhizosphere effect has been linked to increases in microbial abundance and activity due to root exudates providing carbon input, as well as the secretion of surfactant molecules or aromatic compounds homologous to PAHs (reviewed in Martin et al., 2014). Plants can significantly promote $\mathrm{PAH}$ degradation compared to bare soils (Binet et al., 2000; Liu et al., 2013; Storey et al., 2014) and this effect can partially be mimicked by amending soil with root exudates (Miya and Firestone, 2001; Joner et al., 2002). However, contrasting tendencies have been reported in the literature, where plants (Günther et al., 1996; Corgié et al., 2003; Liste and Prutz, 2006; Rezek et al., 2008) or exudates (Cébron et al., 2011; Phillips et al., 2012) can have no effect or even inhibit PAH degradation. So far, few studies have attempted to link PAH degradation to the impact of plants on the quality or quantity of available carbon sources, as well as their effect on the diversity and community composition of the resident and active soil microbiome. Among plant species, grasses offer some advantages for evaluating the rhizosphere effect on organic pollutant degradation and bacterial communities. They possess a fibrous root system allowing intensive penetration of the soil together with large surface area (Aprill and Sims, 1990; Dzantor et al., 2000) and exude high quantities of soluble organic substrates (Lynch and Whipps, 1990). Notably, ryegrass (Lolium perenne) was found as the most effective for PAH rhizoremediation in aged-polluted soil among 18 plant species representing eight families (Olson et al., 2007).

Therefore, the aim of the present study was to investigate the development of ryegrass rhizospheric microbiome in aged PAH-contaminated soil and its short-term influence on pollutant biodegradation. We hypothesized that the selection for specific members of the resident soil bacterial assemblage and changes in abundance and/or transcriptional activity in planted soil would impact PAH degradation, using phenanthrene (PHE) as a model PAH. Here we analyzed rhizospheric soil directly adherent to roots, bulk soil from planted microcosms as well as bare soil from non-planted controls, and compared the short-term dynamics of dissolved organic carbon (DOC), pollution (PHE), resident and active bacterial communities based on DNA/RNA analyses, and potential PAH degraders.

\section{MATERIALS AND METHODS}

\section{Microcosm Set-Up}

Soil from a former coking plant site (NM soil, Neuves-Maisons, France; provided by the GISFI, www.gisfi.fr) was dried at room temperature, sieved to $2 \mathrm{~mm}$ and stored in the dark at room temperature until experimental set-up. Soil characteristics were detailed elsewhere (Cébron et al., 2009). This soil is mostly contaminated with aged PAHs (1260 mg $\Sigma 16$ PAHs. $\mathrm{kg}^{-1}$ ) and to a lesser extent with trace metals. To increase the bioavailability of pollutants, a batch of soil was spiked with phenanthrene (Fluka) at $250 \mathrm{mg} \cdot \mathrm{kg}^{-1}$ as in Thomas et al. (2016). To allow contact of freshly spiked soil with growing roots, two-compartment microcosms were set up as shown in Figure 1. The first and second compartments consisted of the two parts of a sectioned $50 \mathrm{ml}$ plastic syringe (internal diameter $27 \mathrm{~mm}$; Codam Medicals ApS, DK). The first compartment (height $58 \mathrm{~mm}$ ) was filled with $30 \mathrm{~g}$ of non-spiked soil wetted with $6.1 \mathrm{ml}$ of sterile distilled water ( $80 \%$ of the soil water-holding capacity) and closed at the bottom with a nylon filtration mesh (porosity $500 \mu \mathrm{m}$ ). Eight ryegrass seeds (Lolium multiflorum, Italian ryegrass, Podium variety, LG seeds, France) were sown in triplicate first compartments and allowed to germinate at room temperature in the dark. After 3 days, they were transferred to the growth chamber $\left(22 / 18^{\circ} \mathrm{C}\right.$ day/night, $80 \%$ relative humidity, c.a. $250 \mu \mathrm{mol}$ photons $\mathrm{m}^{-2}$ $\mathrm{s}^{-1}, 16 \mathrm{~h}$ photoperiod) and the number of germinated seedlings was reduced to four to ensure similar numbers in all microcosms. Triplicate control first compartments without ryegrass were handled in the same way. Plants were grown until roots reached the bottom of the first compartment. After 20 days, a second compartment (height $15 \mathrm{~mm}$, lined up with aluminum foil to minimize PAH adsorption to plastic and photodegradation) filled with $10 \mathrm{~g}$ of freshly PHE-spiked soil was attached below the first one. A disk of nylon filtration mesh (porosity $500 \mu \mathrm{m}$ ) separated the two compartments to prevent mixing of the two soils. Soil water content was adjusted to $80 \%$ of its waterholding capacity with sterile distilled water throughout the experiment, by weighing the microcosms. Water content did not differ between bare and planted microcosms throughout the experiment (average percent of water retention capacity: bare $=81 \pm 2 \%$; planted $=77 \pm 6 \%$; $t$-test $P=0.50)$. Triplicate microcosms were sacrificed for sampling after 2, $4,6,8$, and 10 days, resulting in 15 bare soil samples and 15 planted samples. To capture the initial state of the soil, second compartments prepared in the same way were sacrificed within $15 \mathrm{~min}$ after rewetting (hereafter "day 0"). All sampling instruments were ethanol-sterilized and cleaned with RNaseZap (Life Technologies) before use. At the time of sampling, a scalpel blade was used to detach the first and second compartment below the nylon mesh disk. Soil from the second compartment was retrieved in a glass Petri dish. For ryegrass-planted microscosms, roots with adhering soil were gently sorted from bulk soil and transferred to another Petri dish. The adhering soil (hereafter "rhizospheric soil") was carefully detached from roots using a brush and tweezers, whereas no further treatment was applied to bulk soil (hereafter "bulk planted soil"). The fresh weight of both 


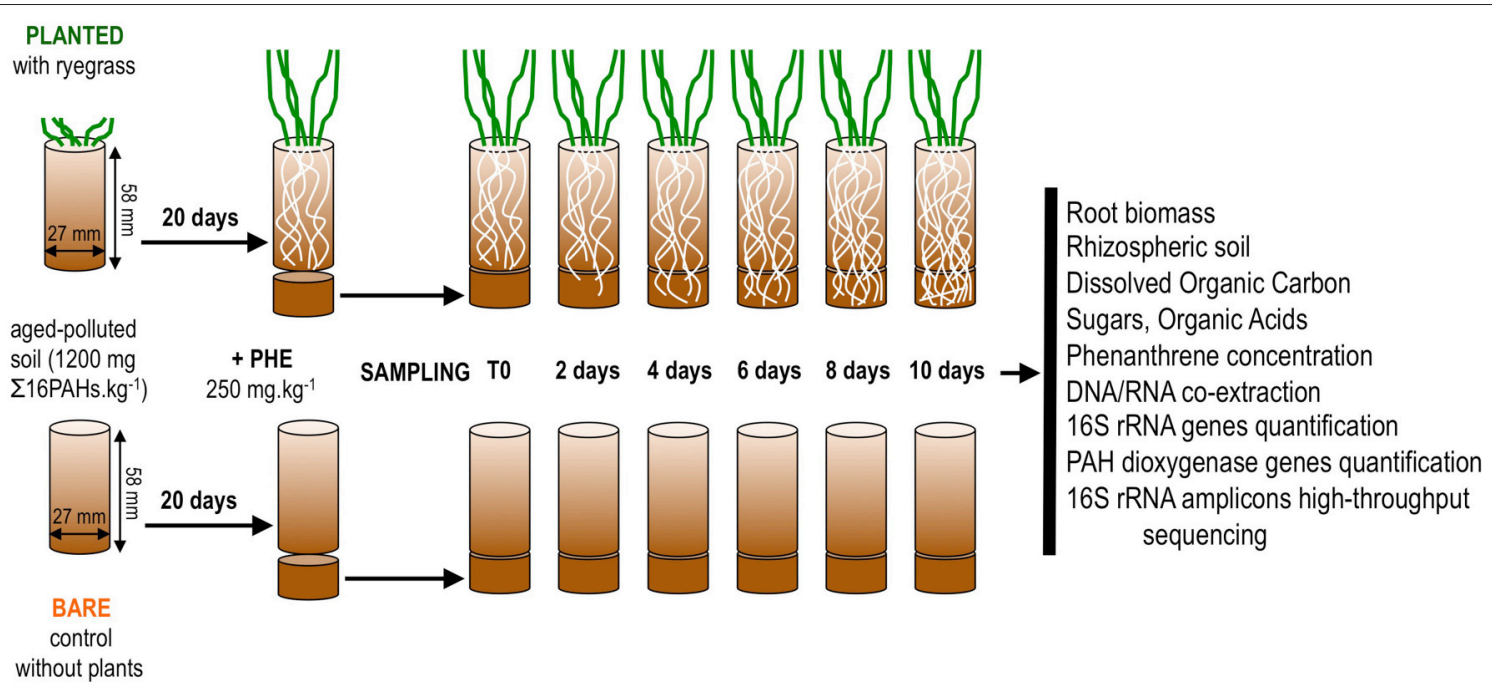

FIGURE 1 | Schematic summary of the microcosm set-up and subsequent sample analyses.

soil fractions was measured on a digital balance (precision $10^{-4}$ g). Roots from the second compartment and shoots were ovendried at $55^{\circ} \mathrm{C}$ for 2 days and weighed. Soil from non-planted microcosms (hereafter "bare soil") was handled the same way. Soil samples were distributed as follows: $1 \mathrm{~g}$ in glass vial for PAH extraction; $0.5 \mathrm{~g}$ in plastic tubes for nucleic acid extraction (immediately frozen in liquid nitrogen); $6 \mathrm{~g}$ in plastic vials for DOC extraction. All samples were stored at $-80^{\circ} \mathrm{C}$ until analysis. The sampling procedure took less than $30 \mathrm{~min}$ for each microcosm.

\section{Organic Analyses}

For PAH extraction and PHE measurement, soil was lyophilized and pulverized in a mixer mill (MM200, Retsch). Soil samples $(250 \mathrm{mg})$ were mixed with diatomaceous earth $(125 \mathrm{mg})$ and extracted with dichloromethane using an high pressure and temperature automated extractor Dionex ASE350 as described elsewhere (Biache et al., 2008). Solvent was exchanged to acetonitrile under nitrogen flux. PHE was quantified by reverse-phase chromatography using an HPLC System (Dionex) equipped with a Pursuit $3 \mathrm{PAH}$ column and a UV-Vis detector set at a wavelength of $254 \mathrm{~nm}$, with a water:acetonitrile gradient.

For total DOC, carbohydrates and organic acids analyses, 6 $\mathrm{g}$ of soil were mixed with $30 \mathrm{ml}$ of distilled water in Teflon tubes and agitated for $2 \mathrm{~h}$ at room temperature (Jones and Willett, 2006). Solutions were recovered by centrifugation at $3000 \mathrm{~g}$ for $10 \mathrm{~min}$ and filtered at $0.45 \mu \mathrm{m}$ (polyester filter Chromafil PET-45/25, Macherey-Nagel). DOC was quantified on a TOC analyzer (TOC-V CSH, Shimadzu). Carbohydrates were measured by ion-exchange chromatography ICS 5000 equipped with a CarboPac SA10 column (Thermo Electron, Dionex) performed at the PTEF INRA-Nancy analytical platform. Sulfate ions were removed from samples prior to organic acid analysis to avoid column saturation. Briefly, aliquots $(4 \mathrm{ml})$ were acidified to $\mathrm{pH} 2$ with concentrated nitric acid, loaded on water-preconditioned Chromafix cartridges (PS-Ba2+,
Macherey-Nagel), and neutralized with $0.2 \mathrm{M} \mathrm{NaOH}$. Organic acids were measured as described elsewhere (Balland et al., 2010) using ion chromatography (ICS 3000, Dionex Corp.) equipped with an IonPac AS 11HC column (Dionex corp.), with conductivity detection.

\section{Nucleic Acid Extraction and cDNA Synthesis}

DNA and RNA were co-extracted from $0.5 \mathrm{~g}$ of soil using an adapted protocol from Wenderoth et al. (2003) with the Fast DNA Spin Kit for Soil (MP Biomedicals, France). Following recovery of DNA according to the manufacturer's instructions, RNA was precipitated from the suspension obtained after sedimentation of the binding matrix with 0.1 vol. $3 \mathrm{M}$ sodium acetate $\mathrm{pH} 5.2$ and 1 vol. isopropanol, overnight at $4{ }^{\circ} \mathrm{C}$. RNA was recovered by centrifugation $45 \mathrm{~min}$ at $19,500 \mathrm{~g}$ and $4^{\circ} \mathrm{C}$, rinsed with 70\% ice-cold ethanol, dried in a vacuum concentrator (Centrivap Jouan RC1010, ThermoScientific) and resuspended in RNase-free water (Gibco, Life Technologies). RNA samples were treated with $1 \mathrm{U}$ of Turbo DNase (Ambion) and purified on RNeasy MinElute Clean-Up kit (Qiagen). Total elimination of DNA from RNA samples was checked by PCR of the 16S rRNA gene. DNA and RNA were quantified in 96-well plates using the Picogreen and Ribogreen assays (Invitrogen), respectively, following the manufacturer's instructions with standard curves from 0.03 to $0.5 \mathrm{ng} \cdot \mu \mathrm{l}^{-1}$. Reverse transcription reactions were performed on $15 \mathrm{ng}$ total RNA using the Superscript III First-Strand synthesis kit (Invitrogen) with random hexamers following the supplier's instructions. DNA and cDNA samples were diluted to 2 ng. $\mu \mathrm{l}^{-1}$ and $0.75 \mathrm{ng}$ eq. RNA. $\mu \mathrm{l}^{-1}$, respectively, and stored at $-20^{\circ} \mathrm{C}$.

\section{Quantitative PCR}

DNA and cDNA fractions were used to quantify bacteria using the primer pair 968F/1401R (Felske et al., 1998), targeting bacterial $16 \mathrm{~S}$ rRNA genes. PAH-ring hydroxylating dioxygenase 
genes from Proteobacteria and Actinobacteria were quantified using the primer pairs PAH-RHD $\alpha$ GN F/R and PAH-RHD $\alpha$ GP F/R, respectively (Cébron et al., 2008). PAH-RHD $\alpha$ genes have been detected in both Gram-negative (GN) and Gram-positive (GP) bacteria. Within GN bacteria, genes have been identified in members of the Alpha-, Beta-, and Gammaproteobacteria and are specifically targeted by the PAH-RHD $\alpha$ GN F/R primer pair. Actinobacteria are the main Gram-positive soil bacteria involved in $\mathrm{PAH}$ degradation, and their PAH-RHD $\alpha$ genes is specifically targeted by the PAH-RHD $\alpha$ GP F/R. Although other bacteria might possess divergent genes that would not be targeted by this primer pair, the current lack of nucleotide sequence precludes the design of new primers. Quantitative PCR was performed as described in Cébron et al. (2008) on a CFX96 real-time system (BioRad). Reactions $(20 \mu \mathrm{l})$ contained 1X iQ SybrGreen Super Mix (BioRad), $12 \mu \mathrm{g}$ bovine serum albumin, $0.2 \mu \mathrm{l}$ dimethyl sulfoxide, $40 \mathrm{ng}$ of $\mathrm{T} 4$ bacteriophage gene 32 product (MP Biomedicals, France), $1 \mu \mathrm{l}$ of template (DNA, cDNA, or 10fold standard plasmid dilution series from $10^{8}$ to $10^{2}$ gene copies. $\mu \mathrm{l}^{-1}$ ) and $8 \mathrm{pmol}$ of each primer. Reactions were heated at $95^{\circ} \mathrm{C}$ for $5 \mathrm{~min}$, followed by 45 cycles of $30 \mathrm{~s}$ at $95^{\circ} \mathrm{C}, 30 \mathrm{~s}$ at the appropriate annealing temperature $\left(56^{\circ} \mathrm{C}\right.$ for $16 \mathrm{~S} \mathrm{rRNA}, 57^{\circ} \mathrm{C}$ for PAH-RHD $\alpha \mathrm{GN}, 54^{\circ} \mathrm{C}$ for PAH-RHD $\alpha \mathrm{GP}$ ), $30 \mathrm{~s}$ at $72^{\circ} \mathrm{C}$ and $10 \mathrm{~s}$ at $82^{\circ} \mathrm{C}$ to capture the fluorescence signal while dissociating primer dimers. Dissociation curves were obtained by heating the PCR products from 50 to $95^{\circ} \mathrm{C}$.

\section{PAH-RHD $\alpha$ Genes Clone Libraries}

Clone libraries were built with PAH-RHD $\alpha$ GN and GP amplicons obtained by qPCR on cDNA fractions from soil after 10 days incubation. qPCR reactions from triplicate microcosms were pooled. Amplicons were purified using the Cycle Pure Kit (Omega Bio-Tek) and cloned in the pGEM-T Vector System (Promega). Plasmids from ampicillin-resistant clones were purified using the E-Z 96 FastFilter Plasmid DNA kit (Omega Bio-Tek) and sequenced in one direction using the M13uni-21 forward primer. Sequences were edited in SeqTrace (Stucky, 2012) to clip PAH-RHD $\alpha$ primers and compared to the NCBI nr database using blastn (Madden, 2002) to retrieve closely related sequences. Alignments for PAH-RHD $\alpha \mathrm{GN}$ and GP produced using MUSCLE (Edgar, 2004) were manually edited in MEGA6 (Tamura et al., 2013), and final versions comprising respectively 251 and 205 ungapped positions were used to infer maximum-likelihood phylogenetic trees with 100 resamplings.

\section{Illumina Tag Sequencing and Analysis}

The V3/V4 region of bacterial 16S rRNA genes was amplified using primers S-D-Bact-0341-a-S-17 (5' CCTACGGGAGGCAGCAG-3') and S-D-Bact-0787-b-A-20 (5'-GGACTACNVGGGTWTCTAAT-3'; Muyzer et al., 1993; Caporaso et al., 2010b) using a previously described dual-index paired-end strategy (Kozich et al., 2013). This primer pair has an overall coverage of $79 \%$ for Bacteria [tested on Silva TestPrime in July 2015, allowing 1 mismatch but no mismatch in the last four bases at $3^{\prime}$-end, (http://www.arb-silva.de/search/testprime/)]. PCR reactions were performed on $1 \mu \mathrm{l}$ of template (DNA or cDNA) in a final volume of $20 \mu \mathrm{l}$, containing $1 \mathrm{X}$ Accuprime
Super Mix (Invitrogen), 10 pmol of each primer (containing Illumina adapter and barcode), $12 \mu \mathrm{g}$ bovine serum albumin, $0.2 \mu \mathrm{l}$ dimethyl sulfoxide and $40 \mathrm{ng}$ of T4 bacteriophage gene 32 product (MPBiomedicals, France). Reactions were heated at $95^{\circ} \mathrm{C}$ for $2 \mathrm{~min}$, followed by 28 cycles of $20 \mathrm{~s}$ at $95^{\circ} \mathrm{C}, 15 \mathrm{~s}$ at $55^{\circ} \mathrm{C}$, $5 \mathrm{~min}$ at $72^{\circ} \mathrm{C}$, and a final extension step for $10 \mathrm{~min}$ at $72^{\circ} \mathrm{C}$. Amplification products were checked by electrophoresis on $1 \%$ agarose gel and purified using the UltraClean-htp 96 Well PCR Clean-Up kit (MOBIO). After quantification by Picogreen assay (Invitrogen), a $10 \mathrm{nM}$ equimolar pool of amplicons was prepared, purified using Nucleospin PCR Clean-Up kit (Macherey-Nagel) and sequenced on a single lane of Illumina Miseq PE250 at the Georgia Genomics Facility (Athens, GA, USA). Paired-end reads trimmed to a minimum QScore of 20 were joined using Pandaseq (Masella et al., 2012) with the following criteria: 400 bp $<$ length $<450$ bp and no ambiguous bases. Sequence data were analyzed using QIIME v1.9 (Caporaso et al., 2010a) and the R package phyloseq (Mcmurdie and Holmes, 2013). Chimeras were detected de novo using UCHIME (Edgar et al., 2011) and sequences were clustered in Operational Taxonomic Units (OTUs) at 97\% similarity using USEARCH v6.1 (Edgar, 2010) implemented in the pick_open_reference_otus.py script in QIIME. Taxonomy was assigned using the RDP classifier (Wang et al., 2007) with the Greengenes database v13_8 (McDonald et al., 2012). OTUs affiliated to mitochondria and chloroplasts were removed for further analysis. Datasets were rarefied to the lowest number of sequences per sample (16,683 reads). Morisita-Horn distance was used for Principal Coordinates Analysis (PCoA), PERMANOVA (adonis), and betadisp tests implemented in vegan (Oksanen et al., 2013). Canonical Correspondance Analysis (CCA) was performed in XLStat 2012 software (Addinsoft) based on the distribution of abundant OTUs ( $>1 \%$ in at least one sample) in cDNA libraries. After checking of variance inflation factors and correlation between environmental variables, acetate (correlated to formate) as well as fructose, sucrose, and xylose (correlated to glucose) were not used for CCA calculation. The detection of bacterial orders with differential abundance was performed in STAMP (Parks et al., 2014). Network modeling was performed separately for bare and bulk planted soil, using data from cDNA libraries with only abundant OTUs ( $>1 \%$ in at least one sample) and environmental parameters. Local similarity analyses were performed using the eLSA software (Xia et al., 2011) with no delay. A total of 93 and 103 parameters were included in the LSA model for bare and bulk planted soil, respectively. LSA results were visualized using Cytoscape v3.1.1 (Shannon et al., 2003). Only associations with $P<0.01$ based on 1000 permutations were considered significant (corresponding to $Q<0.005$ and 0.012 for bare and bulk planted soil, respectively).

\section{Statistical Analysis}

Unless otherwise stated, statistical analyses were performed using R v3.1.3 (R. Core Team, 2013).

\section{Nucleotide Sequence Accession Numbers}

Sequence data for PAH-RHD $\alpha$ GN and GP clone libraries have been deposited in Genbank under accession numbers 
KT948521-KT948566 and KT948567-KT948613, respectively. Illumina MiSeq paired-end reads have been deposited in the SRA database under accession number SRP065058.

\section{RESULTS}

\section{Plant Growth and Soil Carbon Sources}

Following addition of the second compartment to the planted microcosms, ryegrass was actively growing as shown by the increase in aerial biomass, root biomass, and amount of rhizospheric soil over the 10-day kinetics (Figure S1). DOC significantly decreased over time in bare soil, likely due to microbial consumption (Figure 2). In contrast, DOC content stayed stable in bulk planted soil, due to the balance between carbon exudation by plants and microbial consumption. Analysis of soluble organic acids and sugars revealed that bulk planted soils contained significantly more fumarate, mannitol, trehalose, sucrose, glucose, xylose, mannose, and fructose than bare soils, where they were either absent or rapidly depleted. In contrast, the presence of plants tended to decrease gluconate content compared to bare soils. Acetate and formate were rapidly depleted in both conditions, and inositol was only detected in trace amounts.

The initial PHE concentration reached $319 \pm 7 \mu \mathrm{g} . \mathrm{g}^{-1}$ dry weight soil after spiking with fresh PHE (Figure 2) compared to ca. $100 \mu \mathrm{g} . \mathrm{g}^{-1}$ in non-spiked soil. Phenanthrene contamination decreased significantly with time in both bare and bulk planted soil. PHE degradation rates reached respectively $9.9 \pm 2.4$, $6.5 \pm 1.4$, and $5.8 \pm 1.8 \mu \mathrm{g} \cdot \mathrm{g}^{-1} \cdot$ day $^{-1}$ in bare, bulk planted and rhizospheric soil, revealing that plants slowed down PHE biodegradation. After 10 days, concentrations reached significantly lower levels in bare microcosms $\left(214 \pm 17 \mu \mathrm{g} . \mathrm{g}^{-1}\right.$ dry soil, i.e., $48 \%$ degradation of spiked PHE) than in bulk planted $\left(265 \pm 8 \mu \mathrm{g} . \mathrm{g}^{-1}\right.$ dry soil, i.e., $\left.24 \%\right)$ and rhizospheric soil (272 \pm $2 \mu$ g.g ${ }^{-1}$ dry soil, i.e., $\left.21 \%\right)$.

\section{Abundance and Transcriptional Activity of Total Bacterial Community and Potential PAH-Degraders}

Bacterial 16S rRNA gene abundances were similar in bare and bulk planted soil throughout the 10-days time course (Table 1). At day 6, bacterial abundance was 2.3-fold higher in rhizospheric soil compared to bulk planted soil. The transcriptional activity of bacteria (16S rRNA transcripts) increased over one order of magnitude during the first 2 days, and was significantly higher in rhizospheric soil compared to bulk planted soil after 8 and 10 days.

Abundances of PAH-ring hydroxylating dioxygenase (PAH$\mathrm{RH}_{\alpha}$ ) genes from Actinobacteria (GP) were 1-2 orders of magnitude larger than $\mathrm{PAH}-\mathrm{RHD}_{\alpha}$ genes from Proteobacteria (GN) (Table 1). The percentage of PAH-RHD $\mathrm{P}_{\alpha}$ GN relative to $16 \mathrm{~S}$ rRNA gene copies increased rapidly during the first 2 days, and this was more pronounced in bulk planted than bare soil. After 6 days, it started decreasing in bare microcosms but stayed stable and higher in bulk planted and rhizospheric samples. The percentage of PAH- $\mathrm{RHD}_{\alpha}$ GP relative to $16 \mathrm{~S}$ rRNA gene copies decreased over time in bare soil, whereas it increased to significantly higher levels in both bulk planted and rhizospheric samples. For both PAH-RHD ${ }_{\alpha} \mathrm{GN}$ and GP, no difference between bare, bulk planted, and rhizospheric soil could be detected in the number of transcripts relative to 16S rRNA throughout the 10 days time course. Cloning and sequencing of the amplicons retrieved from cDNA after 10 days showed that PAH-RHD ${ }_{\alpha}$ GP clones were related to known sequences from Mycobacterium and Arthrobacter within Actinobacteria (Figure S2), whereas PAH$\mathrm{RHD}_{\alpha} \mathrm{GN}$ clones clustered all with sequences from Pseudomonas (Figure S3).

\section{Dynamics of Bacterial Community Overall Bacterial Community Structure}

After quality filtering, a total of 3,626,425 paired-end sequences were retrieved from the 84 DNA and cDNA $16 \mathrm{~S}$ rRNA libraries, ranging from 16,683 to 106,000 reads per sample. Rarefaction analysis showed that the sequencing effort captured most of the diversity, with curves starting to reach a plateau (Figure S4) and Good's coverage above 97\%. Richness (observed OTUs and Chaol) and diversity indices (Shannon and equitability) were significantly lower in cDNA libraries compared to DNA libraries ( $t$-test, $P<0.001$ for all indices), suggesting that only a subset of the total community was transcriptionally active (Figure 3). At both DNA and cDNA levels, richness was higher in bulk planted and rhizospheric samples compared to bare soil. Both resident and active communities were dominated by Proteobacteria (Alpha-, Beta-, and Gammaproteobacteria classes), Chloroflexi, Firmicutes, and Actinobacteria (Figure 4). Although Acidobacteria, Bacteroidetes, Gemmatimonadetes, and TM7 were detected in DNA libraries (range 0.4-4.0\%), these phyla were not transcriptionally active (representation range in cDNA libraries: 0.01-0.39\%). Correlations between abundances of OTUs in DNA vs. cDNA-based libraries were calculated to inform the contribution of resident bacterial populations to the active community. For all samples, number of reads at DNA and cDNA levels were positively correlated (Table S1, Spearman's $\rho>0.5$ ), showing that in general activity was highly coupled to abundance for a specific OTU. No significant difference was found between the three types of samples at any time point. However, the correlation coefficient between rDNA and rRNA data increased significantly with time, suggesting that a larger proportion of the resident community became active along the 10-days incubation.

\section{Effect of Plant Development on Soil Bacterial Community}

Principal Coordinates Analysis and Permutational Analysis of Variance (Figure S5) evidenced a major effect of the type of nucleic acid (DNA vs. cDNA) and samples (bare vs. bulk planted vs. rhizospheric) on the community composition, as well as an evolution with time. Furthermore, the dispersion of samples retrieved after 6-10 days was significantly higher in bare soil compared to bulk planted and rhizospheric soils, both at DNA (betadisp test, $F=9.4, P<0.001$; average distance to centroid: bare, 0.12 ; planted, 0.02 ; rhizospheric, 0.04$)$ and cDNA level $(F=$ 


\begin{tabular}{|c|c|c|c|c|c|c|c|c|c|c|}
\hline Compound & Condition & $\begin{array}{c}\text { Range } \\
\text { mg.kg-1 dry soil } \\
\end{array}$ & D0 & D2 & D4 & D6 & D8 & D10 & $\begin{array}{l}\text { Time } \\
\text { effect }\end{array}$ & $\begin{array}{l}\text { Plant } \\
\text { effect }\end{array}$ \\
\hline \multirow{2}{*}{$\mathrm{DOC}$} & Bare & $87.0-117.8$ & & & & & & & $<0.001$ & \multirow{2}{*}{$<0.001$} \\
\hline & Bulk planted & $111.2-151.1$ & & & & & & & 0.84 & \\
\hline \multirow{2}{*}{ Gluconate } & Bare & $97.3-119.3$ & & & & & $*$ & $*$ & 0.82 & \multirow{2}{*}{0.02} \\
\hline & Bulk planted & $75.4-110.8$ & & & & & & & 0.12 & \\
\hline \multirow{2}{*}{ Acetate } & Bare & $0.0-11.1$ & & & & & & & $<0.001$ & \multirow{2}{*}{0.7} \\
\hline & Bulk planted & $0.6-11.1$ & & & & & & & 0.01 & \\
\hline \multirow{2}{*}{ Formate } & Bare & $0.3-7.6$ & & & & & & & $<0.001$ & \multirow{2}{*}{0.69} \\
\hline & Bulk planted & $0.5-7.6$ & & & & & & & $<0.001$ & \\
\hline \multirow{2}{*}{ Oxalate } & Bare & $0.0-0.1$ & & & & & & & 0.58 & \multirow{2}{*}{0.13} \\
\hline & Bulk planted & $0.0-0.1$ & & & & & & & 0.09 & \\
\hline \multirow{2}{*}{ Fumarate } & Bare & $0.0-0.5$ & & & & & & & $<0.001$ & \multirow{2}{*}{$<0.001$} \\
\hline & Bulk planted & $0.2-0.5$ & & & & & & & $<0.001$ & \\
\hline \multirow{2}{*}{ Inositol } & Bare & Traces & $\operatorname{Tr}$ & $\operatorname{Tr}$ & $\operatorname{Tr}$ & $\operatorname{Tr}$ & $\operatorname{Tr}$ & $\operatorname{Tr}$ & - & \multirow{2}{*}{-} \\
\hline & Bulk planted & Traces & $\operatorname{Tr}$ & $\operatorname{Tr}$ & $\operatorname{Tr}$ & $\operatorname{Tr}$ & $\operatorname{Tr}$ & $\operatorname{Tr}$ & - & \\
\hline \multirow{2}{*}{ Mannitol } & Bare & $0.0-1.2$ & & $\operatorname{Tr}$ & ND & ND & ND & & 0.03 & \multirow{2}{*}{0.07} \\
\hline & Bulk planted & $0.0-1.2$ & & ND & & & & & 0.18 & \\
\hline \multirow{2}{*}{ Trehalose } & Bare & $0.0-1.2$ & & ND & $\mathrm{Tr}$ & ND & ND & ND & 0.46 & \multirow{2}{*}{0.01} \\
\hline & Bulk planted & $0.0-1.3$ & & & & & & & 0.39 & \\
\hline \multirow{2}{*}{ Sucrose } & Bare & Traces & ND & ND & $\begin{array}{l}\mathrm{Tr} \\
*\end{array}$ & $\underset{*}{N D}$ & $\begin{array}{l}\text { ND } \\
*\end{array}$ & ND & - & \multirow{2}{*}{$<0.001$} \\
\hline & Bulk planted & $0.0-7.3$ & ND & ND & & & & & $<0.001$ & \\
\hline \multirow{2}{*}{ Glucose } & Bare & Traces & $\operatorname{Tr}$ & $\mathrm{Tr}$ & $\operatorname{Tr}$ & ND & ND & ND & 0.46 & \multirow{2}{*}{$<0.001$} \\
\hline & Bulk planted & $0.0-3.5$ & & ND & & & & & 0.24 & \\
\hline \multirow{2}{*}{ Xylose } & Bare & ND & ND & ND & ND & ND & ND & ND & - & \multirow{2}{*}{$<0.001$} \\
\hline & Bulk planted & $0.0-0.9$ & ND & $\operatorname{Tr}$ & & & & & 0.02 & \\
\hline \multirow{2}{*}{ Mannose } & Bare & ND & ND & ND & ND & ND & ND & ND & - & \multirow{2}{*}{0.02} \\
\hline & Bulk planted & $0.0-0.1$ & ND & & & & & & 0.32 & \\
\hline \multirow{2}{*}{ Fructose } & Bare & $0.0-0.1$ & & ND & ND & ND & ND & ND & 0.46 & \multirow{2}{*}{$<0.001$} \\
\hline & Bulk planted & $0.0-6.0$ & & ND & & & & & 0.01 & \\
\hline & Bare & 214-319 & & & & & & & 0.05 & \\
\hline Phenantrene & Bulk planted & $249-319$ & & & & & & & 0.02 & 0.702 \\
\hline & Rhizospheric & $248-276$ & NA & NA & NA & & & & 0.36 & \\
\hline
\end{tabular}

FIGURE 2 | Changes in total dissolved organic carbon (DOC), organic acids, sugars, and phenanthrene concentration in soil extracts over time, in bare and bulk planted soils from day $\mathbf{0}$ (D) to day $\mathbf{1 0}$ (D10). For each compound, maximum detected concentrations were set to 1 and measurements were scaled accordingly. Values are means of three independent replicate microcosms. $P$-values obtained from one-way ANOVAs testing for the overall effect of vegetation and the effect of time for each condition are given. Asterisks between two adjacent cells denote significantly different values between bare and bulk planted soil ( $t$-test, $P<0.05)$

13.5, $P<0.001$; average distance to centroid: bare, 0.17 ; planted, 0.03; rhizospheric, 0.05).

Based on data from cDNA libraries, a total of 12 active bacterial orders showed a significant difference in relative proportion, for at least one time point, between bare and bulk planted or rhizospheric soil (Table 2). Within the first 2 days, ryegrass root development strongly favored Pseudomonadales (seven-fold greater compared to bare soil) and decreased the contribution of Bacillales, Sphingomonadales, and Burkholderiales. Starting from day 4, Caulobacterales 
TABLE 1 | Quantification of bacterial 16S rRNA and PAH-RHD $\alpha$ genes and transcripts in soils from 0 to 10 days.

\begin{tabular}{|c|c|c|c|c|c|c|c|c|}
\hline & & Day 0 & Day 2 & Day 4 & Day 6 & Day 8 & Day 10 & $\begin{array}{l}\text { Time } \\
\text { effect }\end{array}$ \\
\hline \multicolumn{9}{|c|}{ 16S rRNA } \\
\hline \multirow{2}{*}{ DNA } & Bulk planted & - & $5.2 \pm 0.8 \times 10^{8}$ & $4.8 \pm 0.4 \times 10^{8}$ & $3.7 \pm 0.8 \times 10^{8}(\mathrm{~B})$ & $5.1 \pm 0.9 \times 10^{8}$ & $5.7 \pm 0.7 \times 10^{8}$ & n.s. \\
\hline & Rhizospheric & - & - & - & $8.5 \pm 1.2 \times 10^{8}(\mathrm{~A})$ & $6.1 \pm 0.5 \times 10^{8}$ & $8.0 \pm 0.6 \times 10^{8}$ & n.s. \\
\hline cDNA & Rhizospheric & - & - & - & $2.0 \pm 0.6 \times 10^{9}$ & $2.1 \pm 0.8 \times 10^{9}(\mathrm{~A})$ & $2.2 \pm 0.2 \times 10^{9}(\mathrm{~A})$ & n.s. \\
\hline \multicolumn{9}{|c|}{ PAH-RHD $D_{\alpha}$ GN (\% ratio to $\left.16 S\right)$} \\
\hline \multirow[t]{3}{*}{ DNA } & Bare & $0.020 \pm 0.003$ & $0.131 \pm 0.087(\mathrm{~B})$ & $0.509 \pm 0.261$ & $0.099 \pm 0.044(\mathrm{~B})$ & $0.223 \pm 0.046$ & $0.036 \pm 0.020(\mathrm{~B})$ & * \\
\hline & Bulk planted & - & $2.513 \pm 1.107(\mathrm{~A})$ & $1.637 \pm 1.099$ & $0.772 \pm 0.251(\mathrm{~A})$ & $0.498 \pm 0.180$ & $0.407 \pm 0.165(\mathrm{AB})$ & n.s. \\
\hline & Rhizospheric & - & - & - & $1.271 \pm 0.270(\mathrm{~A})$ & $0.821 \pm 0.398$ & $0.611 \pm 0.30(\mathrm{~A})$ & n.s. \\
\hline \multicolumn{9}{|c|}{$P A H-R H D_{\alpha}$ GP (\% ratio to $\left.16 S\right)$} \\
\hline \multirow[t]{3}{*}{ DNA } & Bare & $12.285 \pm 0.950$ & $12.603 \pm 3.674$ & $5.637 \pm 1.763$ & $6.594 \pm 0.615$ & $7.132 \pm 0.138(\mathrm{~B})$ & $4.902 \pm 0.650(\mathrm{~B})$ & * \\
\hline & Bulk planted & - & $7.333 \pm 0.134$ & $8.378 \pm 0.237$ & $7.639 \pm 0.546$ & $11.032 \pm 1.101(\mathrm{~A})$ & $10.175 \pm 0.887(A)$ & ** \\
\hline & Rhizospheric & - & - & - & $6.622 \pm 0.432$ & $11.044 \pm 0.768(\mathrm{~A})$ & $10.256 \pm 0.373(\mathrm{~A})$ & ** \\
\hline \multirow[t]{3}{*}{ cDNA } & Bare & $0.003 \pm 0.003$ & $0.009 \pm 0.006$ & $0.010 \pm 0.005$ & $0.144 \pm 0.133$ & $0.013 \pm 0.007$ & $0.012 \pm 0.007$ & n.s. \\
\hline & Bulk planted & - & $0.009 \pm 0.008$ & $0.137 \pm 0.111$ & $0.033 \pm 0.027$ & $0.025 \pm 0.006$ & $0.118 \pm 0.048$ & n.s. \\
\hline & Rhizospheric & - & - & - & $0.068 \pm 0.057$ & $0.032 \pm 0.009$ & $0.078 \pm 0.045$ & n.s. \\
\hline
\end{tabular}

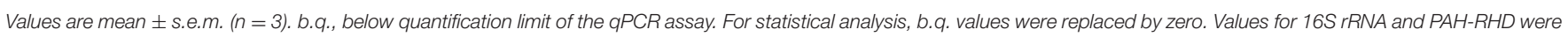

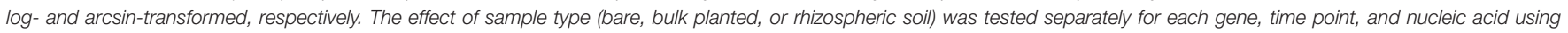

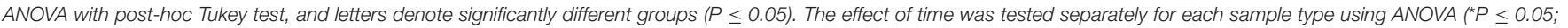
$\left.{ }^{\star \star} P \leq 0.01\right)$.

and Rhizobiales were stimulated by plants and this effect was more pronounced in rhizospheric soil compared to bulk planted soil. Within Actinobacteria, the contribution of Acidimicrobiales and Actinomycetales was higher in planted and rhizospheric samples compared to bare soil after 6 days, whereas Solirubrobacterales were specifically inhibited in rhizospheric soil. Finally, the proportion of Rhodospirillales, Sphingomonadales, and Hydrogenophilales was significantly lower after 10 days with ryegrass and in at least one prior time point.

\section{Structure of OTU-level Bacterial Community in Relation with Environmental Variables}

Canonical Correspondence Analysis (CCA) was used to test the influence of environmental variables on the OTU-level community structure, based on abundant OTUs $(>1 \%$ in at least one sample) in cDNA libraries (Figure 5). The first axis of the CCA was positively correlated to fumarate and DOC, and negatively correlated to phenanthrene degradation rate. It separated samples primarily according to the presence or absence of plants, and secondarily according to the sampling time. Spearman tests confirmed the negative relationship of phenanthrene degradation with DOC $(\rho=-0.33, P=0.006)$, fumarate $(\rho=-0.71, P<0.001)$, acetate $(\rho=-0.52$, $P<0.001)$ and formate $(\rho=-0.60, P=0.001)$. The second axis of the CCA was negatively correlated with formate, and positively correlated with DOC and amount of rhizospheric soil. It mainly separated initial samples (day 0) from all others. OTUs related to Chloroflexi, Actinobacteria (specifically from the Acidimicrobiales and Thermoleophilia), Nitrospira, and Gemmatimonadetes were found predominantly in the soil at day 0 and correlated positively with formate, mannitol, and trehalose. Several OTUs affiliated with Sphingomonas, Sphingobium, Magnetospirillum, and Phenylobacterium and Alcaligenaceae correlated with phenanthrene degradation and prevailed in bare soil from late time points ( $>6$ days). OTUs from Pseudomonas, Cellvibrio, Achromobacter, and Ralstonia were associated with bulk planted soils and correlated with DOC, glucose, mannose, and the amount of rhizospheric soil. Members of Mycoplana, Variovorax, Luteimonas, and Actinomycetales were also associated with bulk planted soils but without strong correlation to measured environmental variables. CCA based on DNA libraries (Figure S6) showed a relatively similar separation of samples according to growth conditions and environmental variables, revealing that changes in the community structure were at least partly visible in the resident community.

Network analysis based on local similarity was used to reveal associations among abundant OTUs $(>1 \%$ in at least one sample) and environmental parameters. Sub-networks organized around PHE degradation included 25 nodes when considering 

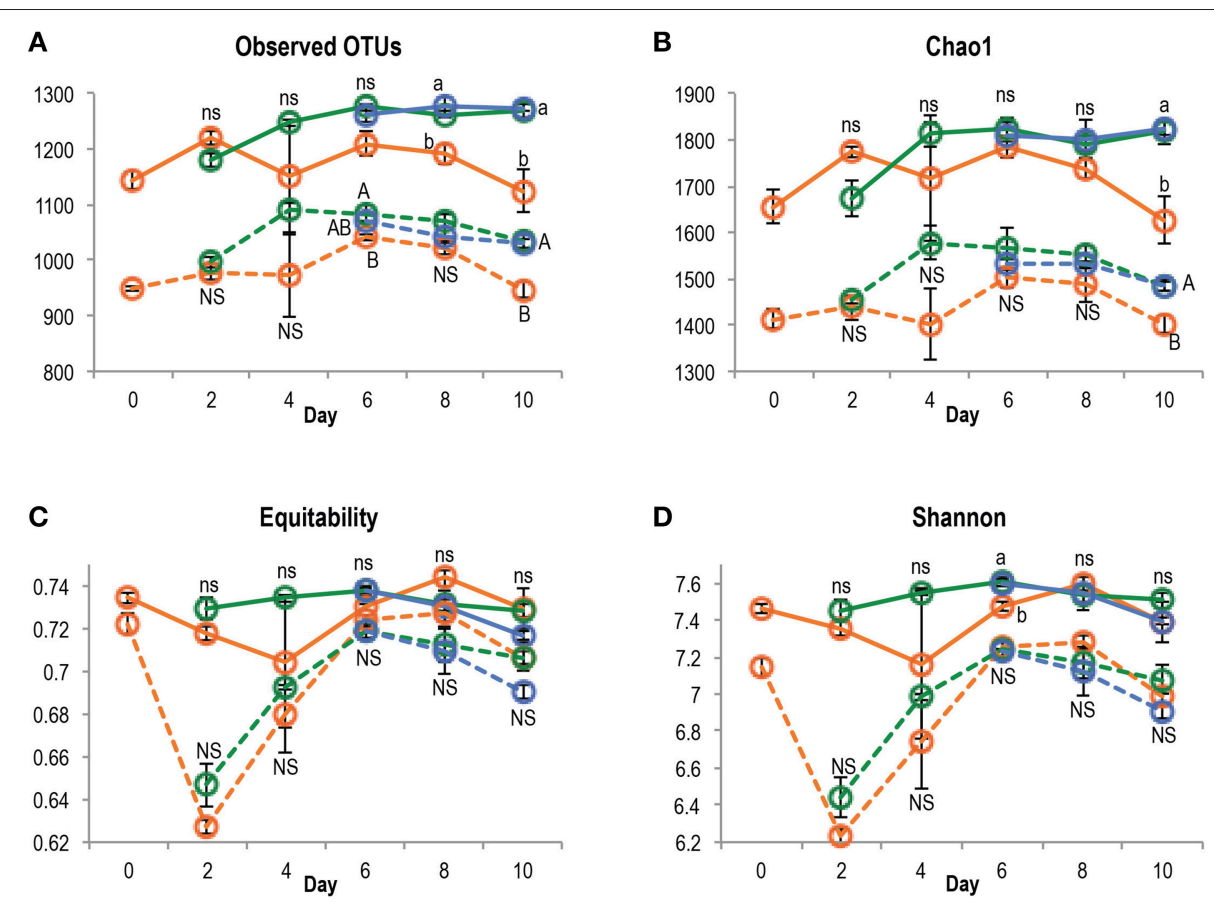

FIGURE 3 | Richness (A, number of OTUs; B, Chao1) and diversity (C, equitability; D, Shannon $\mathrm{H}^{\prime}$ ) indices in bare (orange), bulk planted (green), and rhizospheric soil (blue), based on DNA or cDNA libraries (plain and dotted line, respectively). The effect of sample type was tested separately for each time point and nucleic acid using ANOVA followed by post-hoc Tukey test, and letters denote group with significant difference $(P<0.05)$.

bare soil (Figure 6A) and only seven nodes for bulk planted soil (Figure 6B). Moreover, their degree of connectivity was higher in bare soil, as revealed by larger values of clustering coefficient and average number of neighbors. This suggests that the abundance of bacterial OTUs is more tightly coupled to the use of PHE as a carbon source in bare soil. Notably, PHE degradation was positively associated with a group of eight interconnected OTUs related to Sphingomas, Sphingobium, Paenibacillaceae, Alcaligenaceae, and Arthrobacter in bare soil, and only with 2 OTUs related to Sphingomonadaceae and Variovorax in bulk planted soil. By contrast, concentrations of plant-related labile compounds such as mannose (Figure 6C) and sucrose (Figure 6D) were highly associated with the abundance of OTUs related to Sphingomonas, Sphingobium, Massilia, and Janthinobacterium in bulk planted soil.

\section{DISCUSSION}

\section{Early Development of Rhizospheric Bacterial Communities in An Aged-Contaminated Industrial Soil}

It is well established that the identity, abundance and activity of soil microorganisms depend on a variety of environmental parameters (e.g., soil type, temperature, $\mathrm{pH}$, redox potential, etc.) as well as the presence of plants, their species and their development stage (Fierer and Jackson, 2006; Berg and Smalla, 2009; Reinhold-Hurek et al., 2015). The availability of organic matter is one of the most influential factors in the rhizosphere, since microbial growth in soil is generally carbonlimited (Wardle, 1992; Aldén et al., 2001). So far, knowledge on rhizodeposits derives mainly from systems where plants are grown in sand, inert materials (e.g., glass beads), or hydroponic cultures which might not reflect the quality and/or quantity of exudates released in natural conditions. Only few studies have analyzed rhizodeposits in situ from planted soils (Phillips et al., 2008; Neumann et al., 2009). In the present experiment, colonization of contaminated soil by actively growing roots provided new sources of organic substrates. The presence of plants was associated with higher concentrations of total DOC, as well as fumarate, mannitol, trehalose, sucrose, glucose, xylose, mannose, and fructose. This suggests that some of these molecules directly constitute part of the exudate cocktail released by ryegrass as shown previously in sand matrix (Clayton et al., 2008; Louvel et al., 2011). Moreover, microorganisms might release these simple compounds during the degradation of more complex exudates, breakdown of plant cell wall or as signals in response to the rhizospheric environmental conditions. Fungal species also produce carbohydrates such as trehalose (Elbein et al., 2003) and its detection might therefore be indirectly due to roots favoring fungal communities in planted soils (Thion et al., 2012). In contrast, concentration of other compounds such as acetate, formate, and inositol remained low in bulk planted soils, suggesting that they are either not released by ryegrass or that microbial consumption exceeds rhizodeposition. This modification of the soil carbon content quality and quantity 


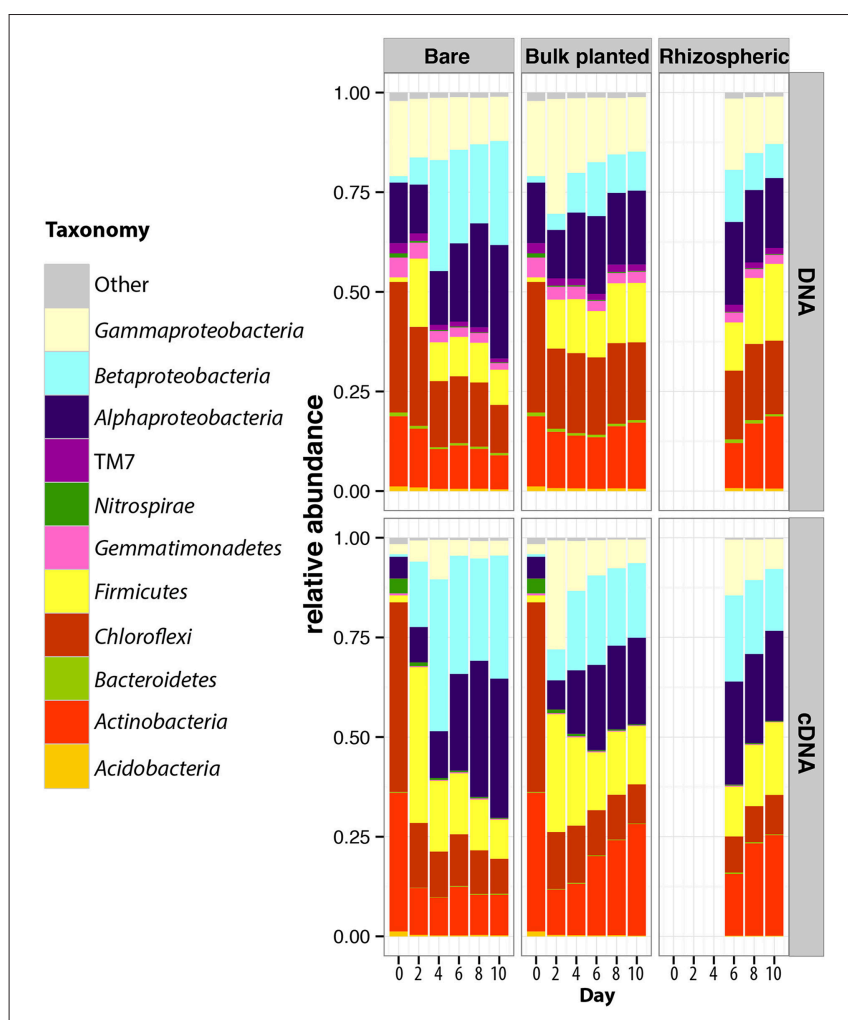

FIGURE 4 | Dynamics of the taxonomic composition of resident and active bacterial communities in bare, bulk planted and rhizospheric soil. Values are mean of three independent microcosms. For comparison, data for day 0 in bare soil were also plotted for bulk planted soil.

in aged PAH-contaminated soil was shown for the first time to be accompanied by early shifts in the resident and active bacterial community structure, even if other plant-induced modifications (e.g., $\mathrm{pH}$, redox conditions, etc.) could contribute. Species richness increased in planted microcosms, contrasting from what is commonly shown in non-contaminated soils where richness or diversity indices are usually lower in the presence of plants (Uroz et al., 2010; Li et al., 2014; Shi et al., 2015), including ryegrass (Marilley et al., 1998). Therefore, increase of bacterial richness as well as diversity in the rhizosphere might be characteristic of polluted soils, since it has already been shown for the same soil (Cébron et al., 2009; Bourceret et al., 2015) and other sites (Shahsavari et al., 2013; Li et al., 2015). This discrepancy could be due to the oligotrophic nature of contaminated soils, where nutrients are scarce and carbon sources are either too recalcitrant or not bio-available. In these extreme environments, plants can provide labile substrates and offer new microniches to favor the development of inactive bacterial species, leading to an increase in richness (Dejonghe et al., 2001). Such structuring of the soil in microniches was evidenced by the increase in transcriptional activity of bacteria, which was restricted to the root-adherent rhizospheric soil compared to bulk planted soil. In addition, plants reduced the variability in the community structure compared to bare soil, suggesting that although increasing spatial heterogeneity, the rhizosphere environment might provide more temporally stable conditions and constrain microbiome assemblage and activity.

The active community composition significantly changed as a result of root colonization. Pseudomonadales were favored early after root colonization (within 2 days) and could be considered as the first rhizosphere-responsive group, followed by Caulobacterales and Rhizobiales (4 days). More diverse communities were active after 6-10 days, notably characterized by members of Acidimicrobiales, Actinomycetales, Caulobacterales, Rhizobiales, Pseudomonadales, and Xanthomonadales. Many studies have previously detected these taxa in the rhizosphere of various plant species in unpolluted soils (DeAngelis et al., 2009; Turner et al., 2013; Chaparro et al., 2014; Li et al., 2014). Reversely, plants strongly selected against members of Sphingomonadales and to a lesser extent Hydrogenophilales, Rhodospirillales, Comamonadaceae, Oxalobacteraceae, and Paenibacillaceae. These shifts in bacterial community composition might be due to the increase in carbon availability via rhizodeposition favoring fast growing r-strategist bacteria (Fierer et al., 2007; Blagodatskaya et al., 2014). Furthermore, Goldfarb et al. (2011) showed a differential response of soil bacteria to substrates of varying chemical recalcitrance, some being favored with labile compounds (e.g., Actinomycetales and Pseudomonadales) and others with more recalcitrant carbon sources (e.g., members of Sphingomonadales). Interestingly, members of Actinomycetales, Rhizobiales Pseudomonadales, and Xanthomonadales were also favored in the same NM soil planted with alfalfa after 37 days in rhizotron experiments (Bourceret et al., in preparation) and after 6 years in a field trial (Bourceret et al., 2015), pointing to an early selection of a rhizospheric community that can persist throughout plant development and seasons.

\section{Early Effects of Plants on Phenanthrene Biodegradation}

During the 10-days time course, the presence of ryegrass slowed down the degradation of spiked phenanthrene although the abundance of PAH RHD $\alpha$ genes increased compared to bare soil. These effects were greatest in root-adherent rhizospheric soil. Rhizodeposits such as simple sugars and organic acids are more bioavailable and energetically favorable than PHE (Providenti et al., 1993; Woo and Rittmann, 2000) and may therefore be preferentially consumed by $\mathrm{PAH}$-degrading bacteria, as revealed by the negative correlation between PHE degradation and DOC content. Although not specifically tested in this study, the reduction of PHE degradation in planted microcosms might also be partially linked to micronutrients depletion in the rhizosphere, possible adsorption of PAHs to roots or changes in $\mathrm{pO}_{2} / \mathrm{pCO}_{2}$ (Joner et al., 2002; Corgié et al., 2003). Previous investigations have proposed that plant-assisted organic pollutant remediation is a balance between the positive effect of rhizodeposits on microbial abundance vs. negative effect due to substrate competition (Kamath et al., 2004; Rentz et al., 2004; He et al., 2005; Fang et al., 2012). Therefore, the positive effect of plants on the abundance of $\mathrm{PAH}$ degraders reported here may on the long-term compensate for the competition with labile 
TABLE 2 | Relative proportion of bacterial orders that significantly $(P<0.05)$ change with plant growth, based on data from cDNA libraries.

\begin{tabular}{|c|c|c|c|c|}
\hline & Bare & Bulk planted & Rhizospheric & $\boldsymbol{P}$ \\
\hline \multicolumn{5}{|l|}{ DAY 2} \\
\hline Firmicutes:Bacilli:Bacillales & $39.0 \pm 1.3$ & $28.5 \pm 2.3$ & - & 0.019 \\
\hline Proteobacteria:Alphaproteobacteria:Sphingomonadales & $1.7 \pm 0.0$ & $1.4 \pm 0.1$ & - & 0.032 \\
\hline Proteobacteria:Betaproteobacteria:Burkholderiales & $16.1 \pm 1.8$ & $6.3 \pm 1.8$ & - & 0.023 \\
\hline Proteobacteria:Gammaproteobacteria:Pseudomonadales & $3.7 \pm 0.4$ & $26.8 \pm 3.6$ & - & 0.006 \\
\hline Proteobacteria:Alphaproteobacteria:Rhizobiales & $1.6 \pm 0.1$ & $2.5 \pm 0.2$ & - & 0.021 \\
\hline \multicolumn{5}{|l|}{ DAY 6} \\
\hline Actinobacteria:Acidimicrobiia:Acidimicrobiales & $5.4 \pm 0.3[\mathrm{~B}]$ & $10.4 \pm 0.3[\mathrm{~A}]$ & $6.5 \pm 0.3[\mathrm{~B}]$ & 0.000 \\
\hline Actinobacteria:Actinobacteria:Actinomycetales & $4.9 \pm 0.1[\mathrm{~B}]$ & $8.2 \pm 0.6[\mathrm{~A}]$ & $8.1 \pm 0.1[\mathrm{~A}]$ & 0.002 \\
\hline Actinobacteria:Thermoleophilia:Solirubrobacterales & $1.1 \pm 0.0[\mathrm{~A}]$ & $1.2 \pm 0.1[\mathrm{~A}]$ & $0.7 \pm 0.0[\mathrm{~B}]$ & 0.001 \\
\hline Proteobacteria:Gammaproteobacteria:Pseudomonadales & $1.6 \pm 0.3[\mathrm{~B}]$ & $5.1 \pm 1.0[\mathrm{AB}]$ & $8.7 \pm 0.8[\mathrm{~A}]$ & 0.004 \\
\hline Proteobacteria:Gammaproteobacteria:Xanthomonadales & $1.6 \pm 0.1[\mathrm{~B}]$ & $2.5 \pm 0.1[\mathrm{~A}]$ & $2.2 \pm 0.1[\mathrm{~A}]$ & 0.004 \\
\hline \multicolumn{5}{|l|}{ DAY 8} \\
\hline Actinobacteria:Acidimicrobiia:Acidimicrobiales & $4.4 \pm 0.1[\mathrm{~B}]$ & $10.0 \pm 0.1[\mathrm{~A}]$ & $8.5 \pm 0.7[\mathrm{~A}]$ & 0.001 \\
\hline Actinobacteria:Actinobacteria:Actinomycetales & $4.4 \pm 0.2[B]$ & $12.7 \pm 0.6[\mathrm{~A}]$ & $13.8 \pm 0.7[A]$ & 0.000 \\
\hline Actinobacteria:Thermoleophilia:Solirubrobacterales & $0.9 \pm 0.1[A]$ & $1.0 \pm 0.1[\mathrm{~A}]$ & $0.6 \pm 0.0[\mathrm{~B}]$ & 0.011 \\
\hline Proteobacteria:Alphaproteobacteria:Rhizobiales & $2.1 \pm 0.1[B]$ & $2.9 \pm 0.1[\mathrm{AB}]$ & $4.5 \pm 0.5[A]$ & 0.012 \\
\hline Proteobacteria:Alphaproteobacteria:Rhodospirillales & $3.1 \pm 0.5[A]$ & $1.1 \pm 0.1[B]$ & $1.0 \pm 0.1[\mathrm{~B}]$ & 0.013 \\
\hline Proteobacteria:Alphaproteobacteria:Sphingomonadales & $20.6 \pm 1.4[A]$ & $7.6 \pm 1.0[B]$ & $6.0 \pm 0.8[B]$ & 0.000 \\
\hline \multicolumn{5}{|l|}{ DAY 10} \\
\hline Actinobacteria:Acidimicrobiia:Acidimicrobiales & $3.9 \pm 0.2[C]$ & $12.0 \pm 0.2[\mathrm{~A}]$ & $8.9 \pm 0.2[B]$ & 0.000 \\
\hline Proteobacteria:Betaproteobacteria:Hydrogenophilales & $5.0 \pm 0.2[\mathrm{~A}]$ & $3.5 \pm 0.2[B]$ & $3.5 \pm 0.1[B]$ & 0.004 \\
\hline
\end{tabular}

Values are mean \pm s.e.m. $(n=3)$ and bold face denote higher levels. For days 2 and 4, values in bare and bulk planted soil were compared using Student t-test. For days 6 , 8 , and 10, the effect of sample type was tested using ANOVA, with post-hoc comparison using Tukey-Kramer test.

substrates or overcome inhibition as the quality and quantity of exudates evolve with ryegrass development. Interestingly, no difference in the number of transcripts of $\mathrm{PAH}-\mathrm{RHD}_{\alpha}$ could be detected between bare and planted soil throughout the kinetics, confirming that root colonization did not induce the expression of PAH-degrading pathways. The relatively low abundance of PAH-RHD transcripts may possibly indicate that the selected primers did not fully target the relevant degrading organisms. However, sequence data obtained from clone libraries confirmed that the amplified sequences were affiliated to Pseudomonas, Arthrobacter, and Mycobacterium, which are known as active $\mathrm{PAH}$ degraders in contaminated soils, including from NeuvesMaisons. Alternatively, the transcription might have increased very transiently before the first time point at day 2 , or the stock of PAH-RHD enzymes in degrading bacteria might be sufficient to process the spiked PHE without an increase in the transcription. This lack of transcriptional induction also suggests that rhizodeposits did not trigger a massive carbon catabolite repression (CCR), which would expectedly yield lower transcription of PAH-RHD genes in planted soil. Purified sugars and root extracts have been shown to inhibit the degradation of aromatic compounds by CCR in several cultivated isolates (Keuth and Rehm, 1991; Dal et al., 2002; Kamath et al., 2004; Rentz et al., 2004; Rojo, 2010; Zhang and Anderson, 2013; Vandera et al., 2015). However, it has been suggested that CCR may be more significant when considering a single species of degrader rather than a diverse community (Martin et al., 2014). Furthermore, the present experimental set-up allowed testing the effect of low and continuous inputs of natural, complex rhizodeposits on autochthonous PAH degraders instead of high concentrations of 


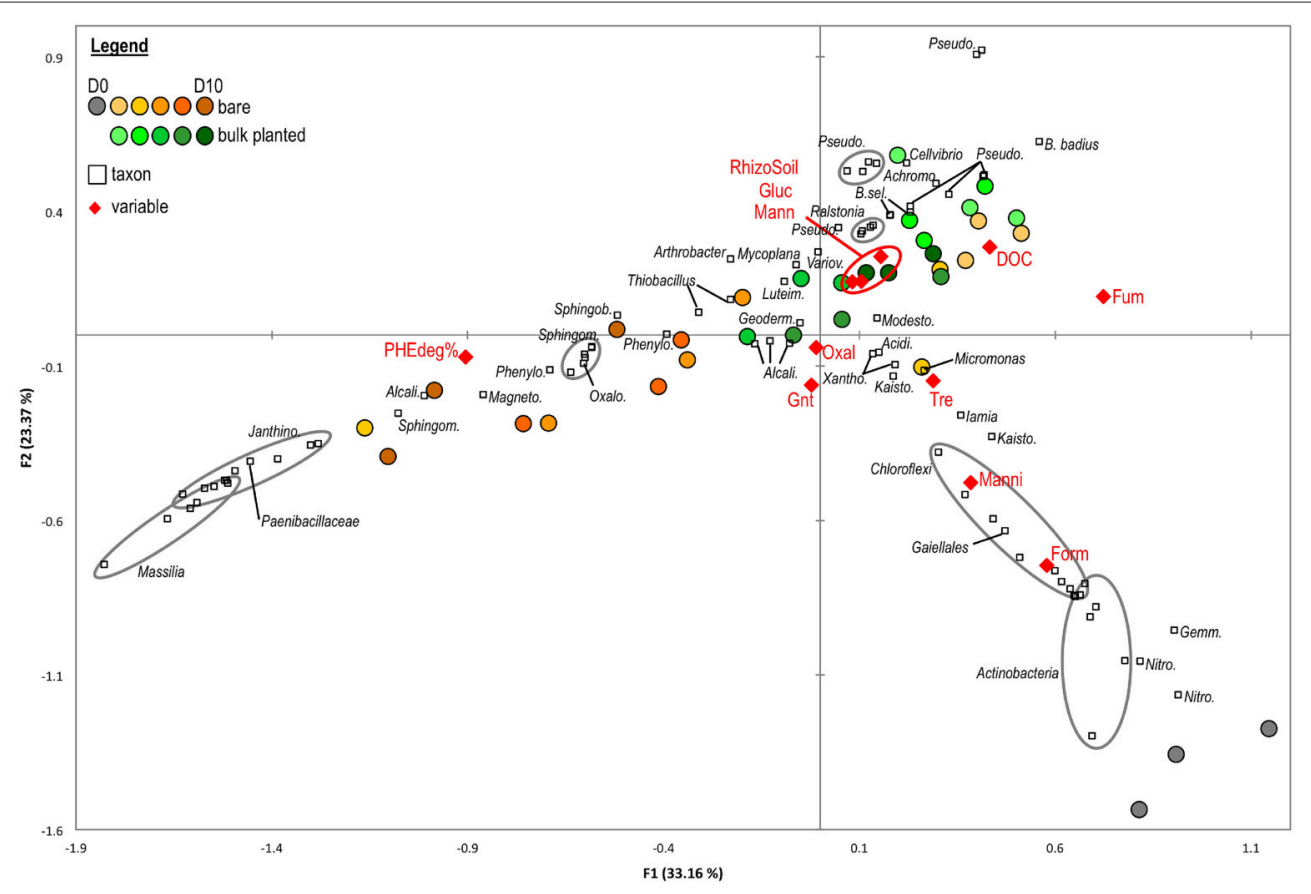

FIGURE 5 | Canonical Correspondance Analysis based on the distribution of abundant OTUs ( $>1 \%$ in at least one sample) in cDNA libraries. The model accounted for $61.6 \%$ of the total inertia, with a global $P$-value $<0.0001$. Circles represent samples from bare (green palette) or bulk planted soil (orange palette). Environmental variables (red diamonds) include percentage of PHE degradation (PHEdeg\%), rhizospheric soil fresh weight (RhizoSoil), total dissolved organic carbon (DOC), glucose (Gluc), mannose (Mann), trehalose (Tre), mannitol (Manni), fumarate (Fum), oxalate (Oxal), gluconate (Gnt), and formate (Form). Squares represent OTUs with their taxonomic affiliation, abbreviated as follows: Janthino., Janthinobacterium; Sphingom., Sphingomonas; Alcali., unclassified Alcaligenaceae; Magneto., Magnetospirillum; Phenylo., Phenlyobacterium; Oxalo., unclassified Oxalobacteraceae; Sphingob., Sphingobium; Geoderm., unclassified Geodermatophilaceae; Luteim., Luteiomas; Variov., Variovorax; Pseudo., Pseudomonas; B. sel., Bacillus selenatarsenatis; Achromo., Achromobacter; B. badius, Bacillus badius; Modesto., Modestobacter; Acidi., unclassified Acidimicrobiales; Xantho., unclassified Xanthomonadaceae; Kaisto., Kaistobacter; Nitro., Nitrospira; Gemm., Gemmatimonadetes. For clarity, only OTUs with contribution $>1 \%$ to at least one axis were depicted.

purified compounds, which might explain that the limited impact of CCR was overlooked so far.

Plants also modified the identity of potential PAH degraders in the NM soil. In bare microcosms, major potential PHE utilizers included representatives of Sphingomonas, Sphingobium, Phenylobacterium and Arthrobacter, the abundance of which was positively correlated with PHE degradation rates. This is concordant with previous results on PHE-spiked agricultural soils, where Sphingomonas became the dominant genus within 2 months, together with a significant increase in Phenylobacterium abundance compared to unspiked controls (Ding et al., 2012). Sphingomonads are known as active hydrocarbon degraders (Peng et al., 2008), often isolated from polluted sites and able to use PHE and other PAHs as sole carbon sources (reviewed in Waigi et al., 2015). In general, sphingomonads feature several adaptive strategies for efficient PAH degradation in oligotrophic environments, such as: (i) adhesion to hydrophobic substrates and formation of biofilm (Johnsen and Karlson, 2004); (ii) the presence of glycosphingolipids in their cell envelope (Kawahara et al., 1999), which are more hydrophobic than common membrane lipids found in other Gram-negative bacteria; and (iii) high affinity uptake systems for recalcitrant compounds (Peng et al., 2008). Interestingly, the relative abundance of members of Sphingomonadales within the active community strongly decreased in planted samples and correlated more with the concentration of simple carbohydrates which have been shown to be used by cultivated Sphingomonas species (Balkwill et al., 1997; Denner et al., 2001). Due to their adaptation to oligotrophy, PAH-degrading sphingomonads might be rapidly outcompeted by other fast-growing soil bacteria in the carbon-rich rhizosphere. In contrast, potential PHEdegraders in planted soil include Pseudomonas, Ralstonia, and Variovorax representatives. Using the same NM soil for a stable isotope probing (SIP) experiment with ${ }^{13} \mathrm{C}$-PHE, Cébron et al. (2011) previously reported that the addition of ryegrass root exudates favored Pseudomonas, which dominated the ${ }^{13} \mathrm{C}$ labeled community. Recent isolation trials for PHE degraders from ryegrass-colonized NM soil retrieved nine new closely related Pseudomonas strains (Thomas et al., 2016), confirming their major role for PHE depollution in planted soils. Bacteria affiliated to Variovorax and Ralstonia were also identified as active PAH-degraders in contaminated soil, in SIP experiments using ${ }^{13} \mathrm{C}$-anthracene and naphthalene (Singleton et al., 2005; Jones et al., 2011a,b). In the future, SIP experiments using ${ }^{13} \mathrm{C}$ labeled PAHs coupled to metagenomics would give invaluable information to evaluate the impact of plant growth and rhizosphere development on the identity of active degraders as well as their metabolic pathways. 
A

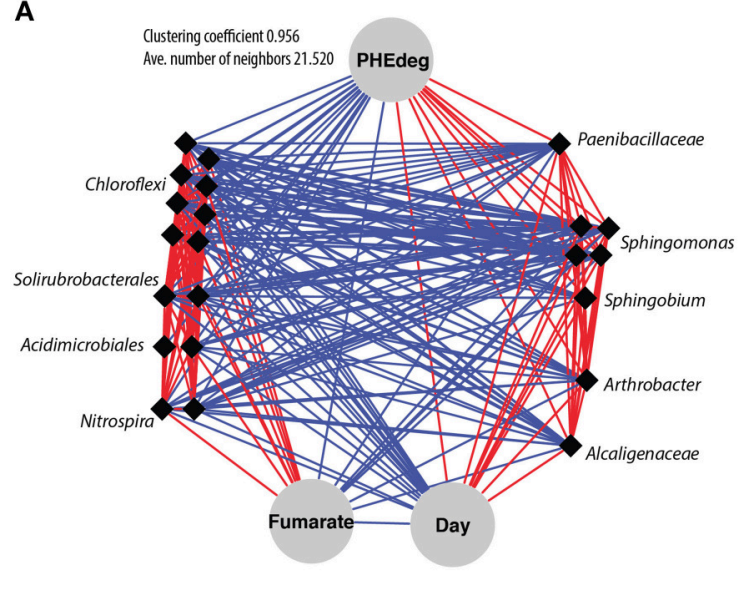

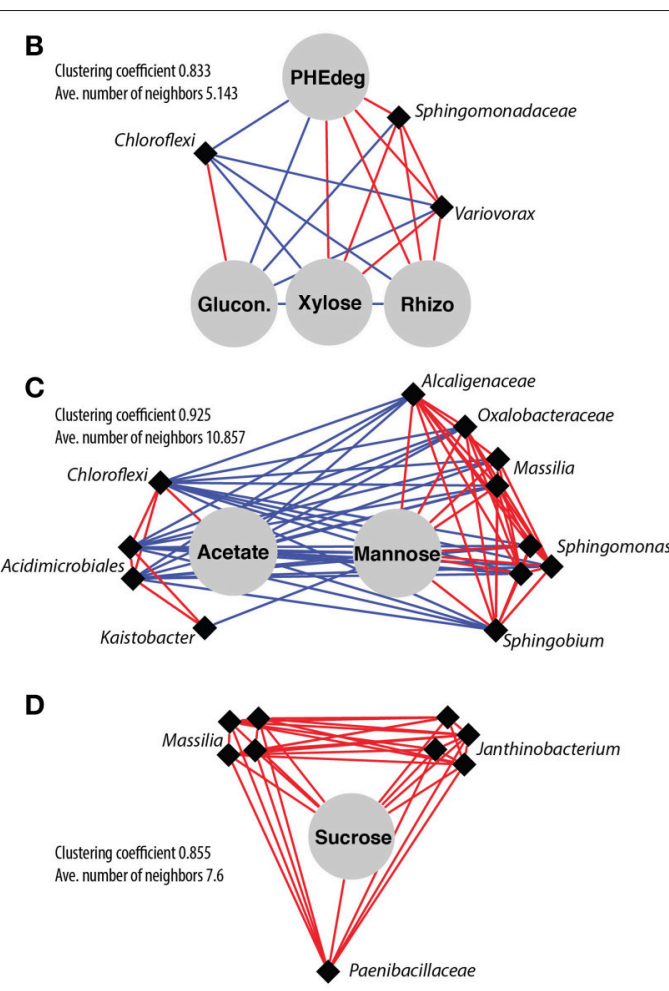

FIGURE 6 | Co-varying networks based on local similarity analysis of abundant OTUs in cDNA libraries (>1\% in at least one sample) and environmental variables. (A) Sub-network from bare soil centered around phenanthrene degradation. (B-D) Sub-networks from bulk planted soil centered around phenanthrene degradation (B), mannose (C), and sucrose (D). Only associations with $P<0.01$ were considered significant $(Q<0.005$ and 0.012 for bare and bulk planted soil, respectively). Red and blue line edges represent positive and negative associations, respectively. OTUs are diamonds (with taxonomy) and environmental factors are circles.

\section{AUTHOR CONTRIBUTIONS}

Designed experiments: FT and AC. Performed experiments: FT. Analyzed results: FT and AC. Wrote the manuscript: FT and AC.

\section{ACKNOWLEDGMENTS}

We would like to thank Géraldine Kitzinger, Florence Coste and David Billet (LIEC, France) as well as Jacqueline Marchand (INRA Champenoux, France) for excellent technical assistance. This study was part of the RhizOrg project funded by the Agence Nationale de la Recherche (ANR-13-JSV7-0007_01).

\section{SUPPLEMENTARY MATERIAL}

The Supplementary Material for this article can be found online at: http://journal.frontiersin.org/article/10.3389/fmicb. 2016.00092

Figure S1 | Evolution of root and aerial dry weight biomass, and rhizospheric soil fresh weight biomass in microcosms planted with ryegrass. Values are mean \pm s.e.m. $(n=3)$.

Figure S2 | Maximum-likelihood (ML) phylogenetic reconstruction of PAH-RHD GP nucleotidic sequences cloned from the Neuves-Maison soil (in boldface), including publicly available sequences from reference strains and uncultured bacteria. The Tamura-Nei model was used for the ML analysis. Values of ML bootstrap support (100 resamplings) greater than $50 \%$ are reported. Unique sequences are represented by one selected clone; numbers of retrieved sequences from bare and bulk planted soil are shown in orange and green boxes, respectively. The tree was rooted on the Rhodococcus/Arthrobacter clade. The bar indicates $5 \%$ sequence divergence.

Figure S3 | Maximum-likelihood (ML) phylogenetic reconstruction of PAH-RHD GN nucleotidic sequences cloned from the Neuves-Maison soil (in boldface), including publicly available sequences from reference strains and uncultured bacteria. The Tamura-Nei model was used for the ML analysis. Values of ML bootstrap support (100 resamplings) greater than $50 \%$ are reported. Unique sequences are represented by one selected clone; numbers of retrieved sequences from bare and bulk planted soil are shown in orange and green boxes, respectively. The tree was rooted on the Polaromonas branch. The bar indicates $2 \%$ sequence divergence.

Figure S4 | Rarefaction curves for OTUs clustered at $97 \%$ similarity.

Figure S5 | Principal Coordinates Analysis (PCoA) displaying the Morisita-Horn dissimilarity between soil bacterial communities, based on DNA and cDNA libraries. Data from bare, bulk planted and rhizospheric soil were analyzed all together but plotted on three superimposable panels for clarity. Permutational Analysis of Variance corroborated the effect of nucleic acid (DNA vs. cDNA; $F=43.0, P<0.001, R^{2}=0.24$ ) and type of samples (bare vs. bulk planted vs. rhizospheric; $F=11.8, P<0.001, R^{2}=0.13$ ) on the community composition, as well as an evolution with time $\left(F=33.7, P<0.001, R^{2}=0.19\right)$.

Figure S6 | Canonical Correspondance Analysis based on the distribution of abundant OTUs ( $>1 \%$ in at least one sample) in DNA libraries. The model accounted for $59.9 \%$ of the total inertia, with a global $P$-value of 0.002 . Circles represent samples from bare (green palette) or bulk planted soil (orange palette). 
Environmental variables (red diamonds) include percentage of PHE degradation (PHEdeg\%), rhizospheric soil fresh weight (RhizoSoil), total dissolved organic carbon (DOC), glucose (Gluc), mannose (Mann), trehalose (Tre), mannitol (Manni), fumarate (Fum), oxalate (Oxal), gluconate (Gnt), and formate (Form). Squares represent OTUs with their taxonomic affiliation, abbreviated as follows: Janthino., Janthinobacterium; Sphingom., Sphingomonas; Alcali., unclassified Alcaligenaceae; Phenylo., Phenlyobacterium; Oxalo., unclassified
Oxalobacteraceae; Sphingob., Sphingobium; Pseudo., Pseudomonas; B. sel., Bacillus selenatarsenatis; Xantho., unclassified Xanthomonadaceae. For clarity, only OTUs with contribution $>1 \%$ to at least one axis were depicted.

\section{Table S1 | Spearman correlation coefficient between DNA and cDNA read}

data. Differences between conditions were tested using ANOVA followed by post-hoc Tukey-Kramer test. Letters denote groups with significant differences $(P<0.05)$.

\section{REFERENCES}

Aldén, L., Demoling, F., and Bååth, E. (2001). Rapid method of determining factors limiting bacterial growth in soil. Appl. Environ. Microbiol. 67, 1830-1838. doi: 10.1128/AEM.67.4.1830-1838.2001

Aprill, W., and Sims, R. C. (1990). Evaluation of the use of prairie grasses for stimulating polycyclic aromatic hydrocarbon treatment in soil. Chemosphere 20, 253-265. doi: 10.1016/0045-6535(90)90100-8

Balkwill, D. L., Drake, G. R., Reeves, R. H., Fredrickson, J. K., White, D. C., Ringelberg, D. B., et al. (1997). Taxonomic study of aromaticdegrading bacteria from deep-terrestrial-subsurface sediments and description of Sphingomonas aromaticivorans sp. nov., Sphingomonas subterranea sp. nov., and Sphingomonas stygia sp. nov. Int. J. Syst. Bacteriol. 47, 191-201. doi: 10.1099/00207713-47-1-191

Balland, C., Poszwa, A., Leyval, C., and Mustin, C. (2010). Dissolution rates of phyllosilicates as a function of bacterial metabolic diversity. Geochim. Cosmochim. Acta 74, 5478-5493. doi: 10.1016/j.gca.2010.06.022

Berg, G., and Smalla, K. (2009). Plant species and soil type cooperatively shape the structure and function of microbial communities in the rhizosphere. FEMS Microbiol. Ecol. 68, 1-13. doi: 10.1111/j.1574-6941.2009.00654.x

Biache, C., Mansuy-Huault, L., Faure, P., Munier-Lamy, C., and Leyval, C. (2008). Effects of thermal desorption on the composition of two coking plant soils: impact on solvent extractable organic compounds and metal bioavailability. Environ. Pollut. 156, 671-677. doi: 10.1016/j.envpol.2008.06.020

Binet, P., Portal, J. M., and Leyval, C. (2000). Dissipation of 3-6-ring polycyclic aromatic hydrocarbons in the rhizosphere of ryegrass. Soil Biol. Biochem. 32, 2011-2017. doi: 10.1016/S0038-0717(00)00100-0

Blagodatskaya, E., Blagodatsky, S., Anderson, T. H., and Kuzyakov, Y. (2014). Microbial growth and carbon use efficiency in the rhizosphere and root-free soil. PLoS ONE 9:e93282. doi: 10.1371/journal.pone.0093282

Bourceret, A., Cébron, A., Tisserant, E., Poupin, P., Bauda, P., Beguiristain, T., et al. (2015). The bacterial and fungal diversity of an aged PAH- and heavy metalcontaminated soil is affected by plant cover and edaphic parameters. Microb. Ecol. doi: 10.1007/s00248-015-0682-8. [Epub ahead of print].

Caporaso, J. G., Kuczynski, J., Stombaugh, J., Bittinger, K., Bushman, F. D., Costello, E. K., et al. (2010a). QIIME allows analysis of highthroughput community sequencing data. Nat. Methods 7, 335-336. doi: 10.1038/nmeth.f.303

Caporaso, J. G., Lauber, C. L., Walters, W. A., Berg-lyons, D., Lozupone, C. A., Turnbaugh, P. J., et al. (2010b). Global patterns of $16 \mathrm{~S}$ rRNA diversity at a depth of millions of sequences per sample. Proc. Natl. Acad. Sci. U.S.A. 108, 4516-4522. doi: 10.1073/pnas.1000080107

Cébron, A., Beguiristain, T., Faure, P., Norini, M.-P., Masfaraud, J.-F., and Leyval, C. (2009). Influence of vegetation on the in situ bacterial community and polycyclic aromatic hydrocarbon (PAH) degraders in aged $\mathrm{PAH}$-contaminated or thermal-desorption-treated soil. Appl. Environ. Microbiol. 75, 6322-6330. doi: 10.1128/AEM.02862-08

Cébron, A., Louvel, B., Faure, P., France-Lanord, C., Chen, Y., Murrell, J. C., et al. (2011). Root exudates modify bacterial diversity of phenanthrene degraders in PAH-polluted soil but not phenanthrene degradation rates. Environ. Microbiol. 13, 722-736. doi: 10.1111/j.1462-2920.2010.02376.x

Cébron, A., Norini, M.-P., Beguiristain, T., and Leyval, C. (2008). Real-Time PCR quantification of PAH-ring hydroxylating dioxygenase (PAH-RHDalpha) genes from Gram positive and Gram negative bacteria in soil and sediment samples. J. Microbiol. Methods 73, 148-159. doi: 10.1016/j.mimet.2008. 01.009

Chaparro, J. M., Badri, D. V., and Vivanco, J. M. (2014). Rhizosphere microbiome assemblage is affected by plant development. ISME J. 8, 790-803. doi: 10.1038/ismej.2013.196

Clayton, S. J., Read, D. B., Murray, P. J., and Gregory, P. J. (2008). Exudation of alcohol and aldehyde sugars from roots of defoliated Lolium perenne L. grown under sterile conditions. J. Chem. Ecol. 34, 1411-1421. doi: 10.1007/s10886008-9536-x

Corgié, S. C., Joner, E. J., and Leyval, C. (2003). Rhizospheric degradation of phenanthrene is a function of proximity to roots. Plant Soil 257, 143-150. doi: 10.1023/A:1026278424871

Dal, S., Steiner, I., and Gerischer, U. (2002). Multiple operons connected with catabolism of aromatic compounds in Acinetobacter sp. strain ADP1 are under carbon catabolite repression. J. Mol. Microbiol. Biotechnol. 4, 389-404.

DeAngelis, K. M., Brodie, E. L., DeSantis, T. Z., Andersen, G. L., Lindow, S. E., and Firestone, M. K. (2009). Selective progressive response of soil microbial community to wild oat roots. ISME J. 3, 168-178. doi: 10.1038/ismej.2008.103

Dejonghe, W., Boon, N., Seghers, D., Top, E. M., and Verstraete, W. (2001). Bioaugmentation of soils by increasing microbial richness: missing links. Environ. Microbiol. 3, 649-657. doi: 10.1046/j.1462-2920.2001.00236.x

Denner, E. B. M., Paukner, S., Kämpfer, P., Moore, E. R. B., Abraham, W. R., Busse, H. J., et al. (2001). Sphingomonas pituitosa sp. nov., an exopolysaccharideproducing bacterium that secretes an unusual type of sphingan. Int. J. Syst. Evol. Microbiol. 51, 827-841. doi: 10.1099/00207713-51-3-827

Ding, G. C., Heuer, H., and Smalla, K. (2012). Dynamics of bacterial communities in two unpolluted soils after spiking with phenanthrene: soil type specific and common responders. Front. Microbiol. 3:90. doi: 10.3389/fmicb.2012.00290

Dzantor, E. K., Chekol, T., and Vough, L. R. (2000). Feasibility of using forage grasses and legumes for phytoremediation of organic pollutants. J. Environ. Sci. Heal. A 35, 1645-1661. doi: 10.1080/10934520009377061

Edgar, R. C. (2004). MUSCLE: multiple sequence alignment with high accuracy and high throughput. Nucleic Acids Res. 32, 1792-1797. doi: 10.1093/nar/gkh340

Edgar, R. C. (2010). Search and clustering orders of magnitude faster than BLAST. Bioinformatics 26, 2460-2461. doi: 10.1093/bioinformatics/btq461

Edgar, R. C., Haas, B. J., Clemente, J. C., Quince, C., and Knight, R. (2011). UCHIME improves sensitivity and speed of chimera detection. Bioinformatics 27, 2194-2200. doi: 10.1093/bioinformatics/btr381

Elbein, A. D., Pan, Y. T., Pastuszak, I., and Carroll, D. (2003). New insights on trehalose: a multifunctional molecule. Glycobiology 13, 17-27. doi: 10.1093/glycob/cwg047

Fang, Y., Yan, C.-L., Du, J.-N., and Yu, J.-Y. (2012). Dependence of phenanthrene dissipation in mangrove sediment on the distance to root surface of Kandelia obovata L. Int. J. Phytoremediation 14, 596-608. doi: $10.1080 / 15226514.2011 .616240$

Felske, A., Akkermans, A. D. L., and De Vos, W. M. (1998). Quantification of $16 \mathrm{~S}$ rRNAs in complex bacterial communities by multiple competitive reverse transcription-PCR in temperature gradient gel electrophoresis fingerprints. Appl. Environ. Microbiol. 64, 4581-4587.

Fierer, N., Bradford, M. A., and Jackson, R. B. (2007). Toward an ecological classification of soil bacteria. Ecology 88, 1354-1364. doi: 10.1890/05-1839

Fierer, N., and Jackson, R. B. (2006). The diversity and biogeography of soil bacterial communities. Proc. Natl. Acad. Sci. U.S.A. 103, 626-631. doi: 10.1073/pnas.0507535103

Gan, S., Lau, E. V., and Ng, H. K. (2009). Remediation of soils contaminated with polycyclic aromatic hydrocarbons (PAHs). J. Hazard. Mater. 172, 532-549. doi: 10.1016/j.jhazmat.2009.07.118 
Goldfarb, K. C., Karaoz, U., Hanson, C. A., Santee, C. A., Bradford, M. A., Treseder, K. K., et al. (2011). Differential growth responses of soil bacterial taxa to carbon substrates of varying chemical recalcitrance. Front. Microbiol. 2:94. doi: 10.3389/fmicb.2011.00094

Günther, T., Dornberger, U., and Fritsche, W. (1996). Effects of ryegrass on biodegradation of hydrocarbons in soil. Chemosphere 33, 203-215. doi: 10.1016/0045-6535(96)00164-6

He, Y., Xu, J., Tang, C., and Wu, Y. (2005). Facilitation of pentachlorophenol degradation in the rhizosphere of ryegrass (Lolium perenne L.). Soil Biol. Biochem. 37, 2017-2024. doi: 10.1016/j.soilbio.2005.03.002

Johnsen, A. R., and Karlson, U. (2004). Evaluation of bacterial strategies to promote the bioavailability of polycyclic aromatic hydrocarbons. Appl. Microbiol. Biotechnol. 63, 452-459. doi: 10.1007/s00253-003-1265-Z

Joner, E. J., Corgié, S. C., Amellal, N., and Leyval, C. (2002). Nutritional constraints to degradation of polycyclic aromatic hydrocarbons in a simulated rhizosphere. Soil Biol. Biochem. 34, 859-864. doi: 10.1016/S0038-0717(02)00018-4

Jones, D., and Willett, V. (2006). Experimental evaluation of methods to quantify dissolved organic nitrogen (DON) and dissolved organic carbon (DOC) in soil. Soil Biol. Biochem. 38, 991-999. doi: 10.1016/j.soilbio.2005.08.012

Jones, M. D., Crandell, D. W., Singleton, D. R., and Aitken, M. D. (2011a). Stable-isotope probing of the polycyclic aromatic hydrocarbon-degrading bacterial guild in a contaminated soil. Environ. Microbiol. 13, 2623-2632. doi: 10.1111/j.1462-2920.2011.02501.x

Jones, M. D., Singleton, D. R., Sun, W., and Aitken, M. D. (2011b). Multiple DNA extractions coupled with stable-isotope probing of anthracene-degrading bacteria in contaminated soil. Appl. Environ. Microbiol. 77, 2984-2991. doi: 10.1128/AEM.01942-10

Kamath, R., Schnoor, J. L., and Alvarez, P. J. J. (2004). Effect of Root-Derived Substrates on the Expression of nah-lux Genes in Pseudomonas fluorescens HK44?: implications for PAH Biodegradation in the Rhizosphere. Environ. Sci. Technol. 38, 1740-1745. doi: 10.1021/es0306258

Kawahara, K., Kuraishi, H., and Zähringer, U. (1999). Chemical structure and function of glycosphingolipids of Sphingomonas spp and their distribution among members of the?alpha-4 subclass of Proteobacteria. J. Ind. Microbiol. Biotechnol. 23, 408-413. doi: 10.1038/sj.jim.2900708

Keuth, S., and Rehm, H.-J. (1991). Biodegradation of phenanthrene by Arthrobacter polychromogenes isolated from a contaminated soil. Appl. Microbiol. Biotechnol. 34, 804-808. doi: 10.1007/bf00169354

Kozich, J. J., Westcott, S. L., Baxter, N. T., Highlander, S. K., and Schloss, P. D. (2013). Development of a dual-index sequencing strategy and curation pipeline for analyzing amplicon sequence data on the MiSeq Illumina sequencing platform. Appl. Environ. Microbiol. 79, 5112-5120. doi: 10.1128/AEM.01043-13

Kuiper, I., Lagendijk, E. L., Bloemberg, G. V., and Lugtenberg, B. J. J. (2004). Rhizoremediation: a beneficial plant-microbe interaction. Mol. Plant. Microbe. Interact. 17, 6-15. doi: 10.1094/MPMI.2004.17.1.6

Li, X., Rui, J., Mao, Y., Yannarell, A., and Mackie, R. (2014). Dynamics of the bacterial community structure in the rhizosphere of a maize cultivar. Soil Biol. Biochem. 68, 392-401. doi: 10.1016/j.soilbio.2013.10.017

Li, Y., Chen, L., and Wen, H. (2015). Changes in the composition and diversity of bacterial communities 13 years after soil reclamation of abandoned mine land in eastern China. Ecol. Res. 30, 357-366. doi: 10.1007/s11284-014-1230-6

Liste, H. H., and Prutz, I. (2006). Plant performance, dioxygenaseexpressing rhizosphere bacteria, and biodegradation of weathered hydrocarbons in contaminated soil. Chemosphere 62, 1411-1420. doi: 10.1016/j.chemosphere.2005.05.018

Liu, S. L., Cao, Z. H., and Liu, H. E. (2013). Effect of ryegrass (Lolium multiflorum L.) growth on degradation of phenanthrene and enzyme activity in soil. Plant Soil Environ. 59, 247-253.

Louvel, B., Cébron, A., and Leyval, C. (2011). Root exudates affect phenanthrene biodegradation, bacterial community and functional gene expression in sand microcosms. Int. Biodeter. Biodegr. 65, 947-953. doi: 10.1016/j.ibiod.2011.07.003

Lynch, J. M., and Whipps, J. M. (1990). Substrate flow in the rhizosphere. Plant Soil 129, 1-10. doi: 10.1007/BF00011685

Madden, T. (2002). The BLAST Sequence Analysis Tool. Bethesda, MD: National Center for Biotechnology Information.

Marilley, L., Vogt, G., Blanc, M., and Aragno, M. (1998). Bacterial diversity in the bulk soil and rhizosphere fractions of Lolium perenne and Trifolium repens as revealed by PCR restriction analysis of 16 S rDNA. Plant Soil 198, 219-224. doi: 10.1023/A:1004309008799

Martin, B. C., George, S. J., Price, C. A., Ryan, M. H., and Tibbett, M. (2014). The role of root exuded low molecular weight organic anions in facilitating petroleum hydrocarbon degradation: current knowledge and future directions. Sci. Total Environ. 472, 642-653. doi: 10.1016/j.scitotenv.2013.11.050

Masella, A. P., Bartram, A. K., Truszkowski, J. M., Brown, D. G., and Neufeld, J. D. (2012). PANDAseq: paired-end assembler for Illumina sequences. BMC Bioinformatics 13:31. doi: 10.1186/1471-2105-13-31

McDonald, D., Price, M. N., Goodrich, J., Nawrocki, E. P., DeSantis, T. Z., Probst, A., et al. (2012). An improved Greengenes taxonomy with explicit ranks for ecological and evolutionary analyses of bacteria and archaea. ISME J. 6, 610-618. doi: 10.1038/ismej.2011.139

Mcmurdie, P. J., and Holmes, S. (2013). Phyloseq: an R package for reproducible interactive analysis and graphics of microbiome census data. PLoS ONE 8:e61217. doi: 10.1371/journal.pone.0061217

Mendes, L. W., Kuramae, E. E., Navarrete, A., A, van Veen, J., A, and Tsai, S. M. (2014). Taxonomical and functional microbial community selection in soybean rhizosphere. ISME J. 1577-1587. doi: 10.1038/ismej.2014.17

Miya, R. K., and Firestone, M. K. (2001). Enhanced phenanthrene biodegradation in soil by slender oat root exudates and root debris. J. Environ. Qual. 30, 1911-1918. doi: 10.2134/jeq2001.1911

Muyzer, G., de Waal, E. C., and Uitterlinden, A. G. (1993). Profiling of complex microbial populations by denaturing gradient gel electrophoresis analysis of polymerase chain reaction-amplified genes coding for 16S rRNA. Apply Environ. Microbiol. 59, 695-700.

Neumann, G., George, T. S., and Plassard, C. (2009). Strategies and methods for studying the rhizosphere-the plant science toolbox. Plant Soil 321, 431-456. doi: 10.1007/s11104-009-9953-9

Oksanen, J., Blanchet, F. G., Kindt, R., Legendre, P., Minchin, P. R., O’Hara, R. B., et al. (2013), vegan: Community Ecology Package. Available at: http://cran.rproject.org/package $=$ vegan

Olson, P. E., Castro, A., Joern, M., DuTeau, N. M., Pilon-Smits, E. A. H., and Reardon, K. F. (2007). Comparison of plant families in a greenhouse phytoremediation study on an aged polycyclic aromatic hydrocarboncontaminated soil. J. Environ. Qual. 36, 1461-1469. doi: 10.2134/jeq2006.0371

Parks, D. H., Tyson, G. W., Hugenholtz, P., and Beiko, R. G. (2014). STAMP: Statistical analysis of taxonomic and functional profiles. Bioinformatics 30, 3123-3124. doi: 10.1093/bioinformatics/btu494

Peng, R.-H., Xiong, A.-S., Xue, Y., Fu, X.-Y., Gao, F., Zhao, W., et al. (2008). Microbial biodegradation of polyaromatic hydrocarbons. FEMS Microbiol. Rev. 32, 927-955. doi: 10.1111/j.1574-6976.2008.00127.x

Phillips, L. A., Greer, C. W., Farrell, R. E., and Germida, J. J. (2012). Plant root exudates impact the hydrocarbon degradation potential of a weathered-hydrocarbon contaminated soil. Appl. Soil Ecol. 52, 56-64. doi: 10.1016/j.apsoil.2011.10.009

Phillips, R. P., Erlitz, Y., Bier, R., and Bernhardt, E. S. (2008). New approach for capturing soluble root exudates in forest soils. Funct. Ecol. 22, 990-999. doi: 10.1111/j.1365-2435.2008.01495.x

Providenti, M. A., Lee, H., and Trevors, J. T. (1993). Selected factors limiting the microbial degradation of recalcitrant compounds. J. Ind. Microbiol. 12, 379-395. doi: 10.1007/B. F.01569669

R. Core Team (2013). R: A Language and Environment for Statistical Computing. Available online at: http://www.r-project.org/

Reinhold-Hurek, B., Bünger, W., Burbano, C. S., Sabale, M., and Hurek, T. (2015). Roots shaping their microbiome: global hotspots for microbial activity. Annu. Rev. Phytopathol. 53, 403-424. doi: 10.1146/annurev-phyto-082712102342

Rentz, J. A., Alvarez, P. J. J., and Schnoor, J. L. (2004). Repression of Pseudomonas putida phenanthrene-degrading activity by plant root extracts and exudates. Environ. Microbiol. 6, 574-583. doi: 10.1111/j.1462-2920.2004.00589.x

Rezek, J., in der Wiesche, C., Mackova, M., Zadrazil, F., and Macek, T. (2008). The effect of ryegrass (Lolium perenne) on decrease of PAH content in long term contaminated soil. Chemosphere 70, 1603-1608. doi: 10.1016/j.chemosphere.2007.08.003

Rojo, F. (2010). Carbon catabolite repression in Pseudomonas: optimizing metabolic versatility and interactions with the environment. FEMS Microbiol. Rev. 34, 658-684. doi: 10.1111/j.1574-6976.2010.00218.x 
Shahsavari, E., Adetutu, E. M., Anderson, P. A., and Ball, A. S. (2013). Tolerance of selected plant species to petrogenic hydrocarbons and effect of plant rhizosphere on the microbial removal of hydrocarbons in contaminated soil. Water Air Soil Pollut. 224:1495. doi: 10.1007/s11270-013-1495-3

Shannon, P., Markiel, A., Ozier, O., Baliga, N. S., Wang, J. T., Ramage, D., et al. (2003). Cytoscape: a software Environment for integrated models of biomolecular interaction networks. Genome Res. 13, 2498-2504. doi: $10.1101 /$ gr.1239303

Shi, S., Nuccio, E., Herman, D. J., Rijkers, R., Estera, K., Li, J., et al. (2015). Successional trajectories of rhizosphere bacterial communities over consecutive seasons. MBio 6, 13-20. doi: 10.1128/mBio.00746-15

Singleton, D. R., Powell, S. N., Sangaiah, R., Gold, A., Ball, L. M., and Aitken, M. D. (2005). Stable-isotope probing of bacteria capable of degrading salicylate, naphthalene, or phenanthrene in a bioreactor treating contaminated soil. Appl. Environ. Microbiol. 71, 1202-1209. doi: 10.1128/AEM.71.3.1202-1209.2005

Storey, S., Ashaari, M. M., Mccabe, G., Harty, M., Dempsey, R., Doyle, O., et al. (2014). Microbial community structure during fluoranthene degradation in the presence of plants. J. Appl. Microbiol. 117, 74-84. doi: 10.1111/jam.12518

Stucky, B. J. (2012). SeqTrace: a graphical tool for rapidly processing DNA sequencing chromatograms. J. Biomol. Tech. 23, 90-93. doi: 10.7171/jbt.122303-004

Tamura, K., Stecher, G., Peterson, D., Filipski, A., and Kumar, S. (2013). MEGA6: molecular evolutionary genetics analysis version 6.0. Mol. Biol. Evol. 30, 2725-2729. doi: 10.1093/molbev/mst197

Thion, C., Cébron, A., Beguiristain, T., and Leyval, C. (2012). Long-term in situ dynamics of the fungal communities in a multi-contaminated soil are mainly driven by plants. FEMS Microbiol. Ecol. 82, 169-181. doi: 10.1111/j.15746941.2012.01414.x

Thomas, F., Lorgeoux, C., Faure, P., Billet, D., and Cébron, A. (2016). Isolation and substrate screening of polycyclic aromatic hydrocarbon degrading bacteria from soil with long history of contamination. Int. Biodeter. Biodegr. 107, 1-9. doi: 10.1016/j.ibiod.2015.11.004

Trivedi, P., He, Z., Van Nostrand, J. D., Albrigo, G., Zhou, J., and Wang, N. (2012). Huanglongbing alters the structure and functional diversity of microbial communities associated with citrus rhizosphere. ISME J. 6, 363-383. doi: 10.1038/ismej.2011.100

Turner, T. R., Ramakrishnan, K., Walshaw, J., Heavens, D., Alston, M., Swarbreck, D., et al. (2013). Comparative metatranscriptomics reveals kingdom level changes in the rhizosphere microbiome of plants. ISME J. 7, 2248-2258. doi: 10.1038/ismej.2013.119

Uroz, S., Buée, M., Murat, C., Frey-Klett, P., and Martin, F. (2010). Pyrosequencing reveals a contrasted bacterial diversity between oak rhizosphere and surrounding soil. Environ. Microbiol. Rep. 2, 281-288. doi: 10.1111/j.1758 2229.2009.00117.x

Vandera, E., Samiotaki, M., Parapouli, M., Panayotou, G., and Koukkou, A. I. (2015). Comparative proteomic analysis of Arthrobacter phenanthrenivorans Sphe3 on phenanthrene, phthalate and glucose. J. Proteomics 113, 73-89. doi: 10.1016/j.jprot.2014.08.018

Waigi, M. G., Kang, F., Goikavi, C., Ling, W., and Gao, Y. (2015). Phenanthrene biodegradation by sphingomonads and its application in the contaminated soils and sediments: a review. Int. Biodeter. Biodegr. 104, 333-349. doi: 10.1016/j.ibiod.2015.06.008

Wang, Q., Garrity, G. M., Tiedje, J. M., and Cole, J. R. (2007). Naive Bayesian classifier for rapid assignment of rRNA sequences into the new bacterial taxonomy. Appl. Environ. Microbiol. 73, 5261-5267. doi: 10.1128/AEM. 00062-07

Wardle, D. A. (1992). A comparative assessment of factors which influence microbial biomass carbon and nitrogen levels in soil. Biol. Rev. 67, 321-258. doi: 10.1111/j.1469-185X.1992.tb00728.x

Wenderoth, D. F., Ferslev, B., Macarri, G., Molinari, G., Lünsdorf, H., and Timmis, K. N. (2003). Leitbakteria of microbial biofilm communities causing occlusion of biliary stents. Environ. Microbiol. 5, 859-866. doi: 10.1046/j.14622920.2003.00513.x

Woo, S. H., and Rittmann, B. E. (2000). Microbial energetics and stoichiometry for biodegradation of aromatic compounds involving oxygenation reactions. Biodegradation 11, 213-227. doi: 10.1023/A:1011162830401

Xia, L. C., Steele, J. A., Cram, J. A., Cardon, Z. G., Simmons, S. L., Vallino, J. J., et al. (2011). Extended local similarity analysis (eLSA) of microbial community and other time series data with replicates. BMC Syst. Biol. 5:S15. doi: 10.1186/1752-0509-5-S2-S15

Zhang, C., and Anderson, A. J. (2013). Utilization of pyrene and benzoate in Mycobacterium isolate KMS is regulated differentially by catabolic repression. J. Basic Microbiol. 53, 81-92. doi: 10.1002/jobm.201100480

Conflict of Interest Statement: The authors declare that the research was conducted in the absence of any commercial or financial relationships that could be construed as a potential conflict of interest.

Copyright (c) 2016 Thomas and Cébron. This is an open-access article distributed under the terms of the Creative Commons Attribution License (CC BY). The use, distribution or reproduction in other forums is permitted, provided the original author(s) or licensor are credited and that the original publication in this journal is cited, in accordance with accepted academic practice. No use, distribution or reproduction is permitted which does not comply with these terms. 